\title{
Berry flavonoids and phenolics: bioavailability and evidence of protective effects
}

\author{
Daniele Del Rio ${ }^{1}$, Gina Borges ${ }^{2}$ and Alan Crozier $^{2} *$ \\ ${ }^{1}$ Human Nutrition Unit, Department of Public Health, University of Parma, Via Volturno 39, 43100 Parma, Italy \\ ${ }^{2}$ Plant Products and Human Nutrition Group, School of Medicine, College of Medical, Veterinary and Life Sciences, Graham Kerr \\ Building, University of Glasgow, Glasgow G12 8QQ, UK
}

(Received 25 January 2010 - Accepted 24 February 2010)

Berries contain vitamin $\mathrm{C}$ and are also a rich source of phytochemicals, especially anthocyanins which occur along with other classes of phenolic compounds, including ellagitannins, flavan-3-ols, procyanidins, flavonols and hydroxybenzoate derivatives. This review examines studies with both human subjects and animals on the absorption of these compounds, and their glucuronide, sulphate and methylated metabolites, into the circulatory system from the gastrointestinal tract and the evidence for their localisation within the body in organs such as the brain and eyes. The involvement of the colonic microflora in catabolising dietary flavonoids that pass from the small to the large intestine is discussed along with the potential fate and role of the resultant phenolic acids that can be produced in substantial quantities. The in vitro and in vivo bioactivities of these polyphenol metabolites and catabolites are assessed, and the current evidence for their involvement in the protective effects of dietary polyphenols, within the gastrointestinal tract and other parts of the body to which they are transported by the circulatory system, is reviewed.

Dietary polyphenols: Bioavailability: Metabolism: Matrix effects: Protective effects

\section{Flavonoids and phenolic compounds in berries and other selected fruits}

Berries contain vitamin $\mathrm{C}$ and are a rich source of phytochemicals, in particular anthocyanins. They also contain ellagitannins, flavan-3-ols, procyanidins, flavonols and hydroxybenzoate derivatives. The anthocyanins are conjugated anthocyanidins, which provide the distinctive and vibrant palette of colours found in berries. There are six main anthocyanidins distributed throughout the plant kingdom: cyanidin, malvidin, delphinidin, peonidin, petunidin and pelargonidin (Fig. 1). They form $O$-linked conjugates with a number of sugars, in particular glucose, sophorose, rutinose, rhamnose, galactose, arabinose and xylose.

Concentrations of phytochemicals in berries will be influenced by many factors including environmental conditions, degree of ripeness, cultivar, cultivation site, processing and storage of the fruit ${ }^{(1-3)}$. The structures of the predominant anthocyanins are summarised in Fig. 2 and are listed in more detail along with other flavonoids and phenolic compounds in Table $1^{(4-16)}$. There is much variety, and while some fruits, such as redcurrants (Rubus idaeus) and elderberry (Sambucus nigra), contain derivatives of only one type of anthocyanin (i.e. cyanidin), a wide array of anthocyanins is found in blueberry (Vaccinium corymbosum), bilberry (Vaccinium myrtillus) and blackcurrant (Ribes nigrum). In general, the anthocyanin profile of a tissue is characteristic, and it has been used in taxonomy, as well as for the detection of adulteration of juices and wines. Blackcurrants are characterised by the presence of the rutinosides and glucosides of delphinidin and cyanidin, with the rutinosides being the most abundant. Other anthocyanins occur but at much lower concentrations. While redcurrants are very closely related to blackcurrants, they contain mainly cyanidin diglycosides with cyanidin monoglucosides present only as minor components. Strawberries (Fragaria $\times$ ananassa), blackberries (Rubus spp.) and red raspberries (R. idaeus) are all from the Rosaceae family but they have a diverse anthocyanin content. The major anthocyanins in raspberries and blackberries are derivatives of cyanidin, while in strawberries, pelargonidin3-O-glucoside predominates. The major components in blueberries are malvidin-3-O-arabinoside and the 3-O-galactosides of cyanidin, delphinidin, petunidin and malvidin, with many minor anthocyanins also being present. Cranberries belong to the Ericaceae, the same family as blueberries, but have cyanidin- and peonidin-based compounds as their major anthocyanins (Table 1, Fig. 2).

Flavonols and other flavonoids are commonly quantified as the aglycone after acid or enzyme hydrolysis to remove sugar residue $^{(17,18)}$. Using this approach, the myricetin, quercetin and kaempferol content of edible berries had been estimated $^{(19)}$. Quercetin was found to be highest in bog whortleberry (Vaccinium uliginosum) $(158 \mathrm{mg} / \mathrm{kg})$ and bilberry $(17-30 \mathrm{mg} / \mathrm{kg})$. In blackcurrant cultivars, myricetin was the

Abbreviations: $C_{\max }$, peak plasma concentration; $T_{\max }$, maximum time.

* Corresponding author: A. Crozier, fax +44 141 3305394, email alan.crozier@gla.ac.uk 
<smiles></smiles>

\begin{tabular}{llll}
\hline Anthocyanidin & $\mathrm{R}_{1}$ & $\mathrm{R}_{2}$ & Colour \\
\hline Pelargonidin & $\mathrm{H}$ & $\mathrm{H}$ & Orange-red \\
Cyanidin & $\mathrm{OH}$ & $\mathrm{H}$ & Red \\
Delphinidin & $\mathrm{OH}$ & $\mathrm{OH}$ & Pink \\
Peonidin & $\mathrm{OCH}_{3}$ & $\mathrm{H}$ & Bluish purple \\
Petunidin & $\mathrm{OCH}_{3}$ & $\mathrm{OH}$ & Purple \\
Malvidin & $\mathrm{OCH}_{3}$ & $\mathrm{OCH}_{3}$ & Redish purple \\
\hline
\end{tabular}

Fig. 1. Anthocyanidin structures.

most abundant flavonol $(89-203 \mathrm{mg} / \mathrm{kg})$, followed by quercetin $(70-122 \mathrm{mg} / \mathrm{kg}$ ) and kaempferol $(9-23 \mathrm{mg} / \mathrm{kg})$. In comparison, the total anthocyanin content of red raspberries is approximately $600 \mathrm{mg} / \mathrm{kg}^{(11,12)}$. Specific flavonol glycosides that have been identified in berries include quercetin-3- $O$ glucoside, quercetin-3-O-rutinoside, quercetin-3-O-galactoside and quercetin-3-O-xylosylglucuronide, myricetin-3-O-glucoside, myricetin-3-O-galactoside and myricetin-3-O-rutinoside (Fig. 3, Table 1).

Berries can contain the flavan-3-ol monomers $(+)$-catechin and $(-)$-epicatechin as well as dimers, trimers and polymeric proanthocyanidins (Fig. 4). The concentration of the polymers is usually greater than the monomers, dimers and trimers, and overall cranberries are a particularly rich source of these compounds (Table 2$)^{(5,20)}$.

The hydroxybenzoate, ellagic acid (Fig. 5), has been reported in berries, particularly raspberries $(5.8 \mathrm{mg} / \mathrm{kg})$, strawberries $(18 \mathrm{mg} / \mathrm{kg})$ and blackberries $(88 \mathrm{mg} / \mathrm{kg})^{(21)}$. Indeed, ellagic acid has been described as being responsible for $>50 \%$ of total phenolics quantified in strawberries and raspberries $^{(22)}$. In reality, however, free ellagic acid levels are generally low, although substantial quantities are detected along with gallic acid after acid hydrolysis of extracts as a product of ellagitannin breakdown (Fig. 5). For instance, red raspberries, the health benefits of which are often promoted on the basis of a high ellagic acid content, contain approximately $1 \mathrm{mg} / \mathrm{kg}$ of ellagic acid compared to approximately $300 \mathrm{mg} / \mathrm{kg}$ of ellagitannins, mainly in the form of sanguiin H-6 and lambertianin C (Fig. 5) ${ }^{(11,13)}$. Pomegranates (Punica granatum L.) also contain a high concentration of ellagitannins. The fruit contains gallagic acid, an analogue of ellagic acid, based on four gallic acid residues, and punicalin, the principal monomeric ellagitannin in which gallagic acid is bound to glucose. Punicalagin is a further ellagitannin in which ellagic acid, as well as gallagic acid, is linked to glucose moiety (Fig. 6) ${ }^{(23)}$. Several ellagitannin monomers, dimers, trimers and tetramers had been identified in blackberries but most occur only in seed tissues ${ }^{(10)}$.
A variety of hydroxycinnamates, including chlorogenic acids, are also found in berries but usually they are present in low concentrations ${ }^{(24)}$, although in other fruits, including apples, 5-O-caffeoylquinic acid can accumulate in more substantial concentrations. Concord purple grapes (Vitis labrusca) contain the hydroxycinnamate-tartaric acid conjugates coutaric acid and caftaric acid (Fig. 7) ${ }^{(23)}$.

\section{Bioavailability of flavonoids and phenolic compounds}

Following the ingestion of dietary flavonoids which, with the notable exception of flavan-3-ols, exist in planta predominantly as glycoside conjugates, absorption of some but not all components into the circulatory system occurs in the small intestine ${ }^{(25)}$. Typically, this is associated with hydrolysis, releasing the aglycone, as a result of the action of lactase phloridizin hydrolase in the brush border of the small intestine epithelial cells. Lactase phloridizin hydrolase exhibits broad substrate specificity for flavonoid- $O$ - $\beta$-D-glucosides, and the released aglycone may then enter the epithelial cells by passive diffusion as a result of its increased lipophilicity and its proximity to the cellular membrane ${ }^{(26)}$. An alternative site of hydrolysis is a cytosolic $\beta$-glucosidase within the epithelial cells. In order for cytosolic $\beta$-glucosidase-mediated hydrolysis to occur, the polar glucosides must be transported into the epithelial cells, possibly with the involvement of the active Na-dependent GLUT- $1^{(27)}$. Thus, it has been accepted that there are two possible routes by which the glucoside conjugates are hydrolysed, and the resultant aglycones appear in the epithelial cells, namely 'lactase phloridizin hydrolase/ diffusion' and 'transport/cytosolic $\beta$-glucosidase'. However, a recent investigation, in which Na-dependent GLUT-1 was expressed in Xenopus laevis oocytes, indicated that SLGT1 does not transport flavonoids and that glycosylated flavonoids, and some aglycones, have the capability to inhibit the GLUT ${ }^{(28)}$.

Before passage into the bloodstream, the aglycones undergo metabolism forming sulphate, glucuronide and/or methylated metabolites through the respective action of sulphotransferases, UDP-glucuronosyltransferases and catechol- $O$-methyltransferases. There is also efflux of at least some of the metabolites back into the lumen of the small intestine, and this is thought to involve members of the ATP-binding cassette family of transporters including multidrug resistance protein and P-glycoprotein. Once in the bloodstream, metabolites can be subjected to phase II metabolism with further conversions occurring in the liver, where enterohepatic transport in the bile may result in some recycling back to the small intestine ${ }^{(25)}$. Flavonoids and their metabolites not absorbed in the small intestine can be absorbed in the large intestine where the colonic microflora that will cleave conjugating moieties and the resultant aglycones will undergo ring fission leading to the production of phenolic acids and hydroxycinnamates. These can be absorbed and may be subjected to phase II metabolism in the liver before being excreted in urine in substantial quantities that, in most instances, are well in excess of the flavonoid metabolites that enter the circulatory system via the small intestine ${ }^{(29-31)}$.

A detailed review on the bioavailability of polyphenols in human subjects by Manach et al. ${ }^{(32)}$ was published in 2005. Much of the research covered involved feeding volunteers a single supplement and monitoring the levels of flavonoids in 


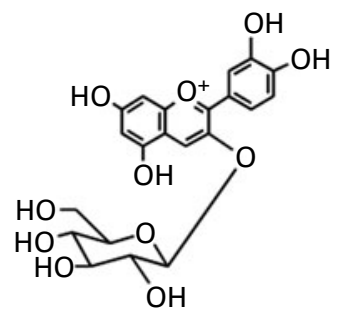

Cyanidin-3-O-glucoside (Blackberry, Strawberry, Elderberry)<smiles>Oc1cc(O)c2cc(-c3ccc(O)c(O)c3)[o+](-c3ccc(O)c(O)c3)c2c1</smiles>

Cyanidin-3-O-galactoside (Cranberry)<smiles>OCC1OC(O)C(O)C(O)C(O)C1Oc1cc(O)c2cc(-c3ccc(O)cc3)oc2c1</smiles>

Pelargonidin-3-O-glucoside (Strawberry)<smiles>Oc1cc2c(cc1O)C(c1cc(O)c(O)c(O)c1)C(O)C(O)C1OC(O2)C(O)C(O)C1O</smiles>

Dephinidin-3-O-galactoside (Blueberry)<smiles>COc1cc(-c2cc3c(O)cc(O)cc3[o+]c2Oc2cc(O)c(O)c(O)c2)cc(O)c1OCC(O)C(O)CO</smiles>

Petunidin-3-O-glucoside (Blueberry)<smiles>Oc1ccc2[o+]c(-c3ccc(O)c(O)c3)c(O)cc2c1</smiles>

Cyanidin-3-O-arabinoside (Cranberry)

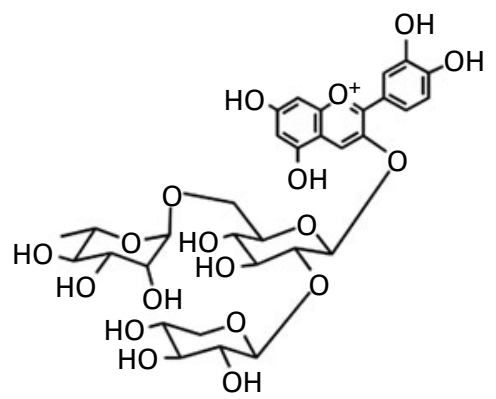

Cyanidin-3-O-(2"-O-xylosyl)rutinoside (Redcurrant, Raspberry)

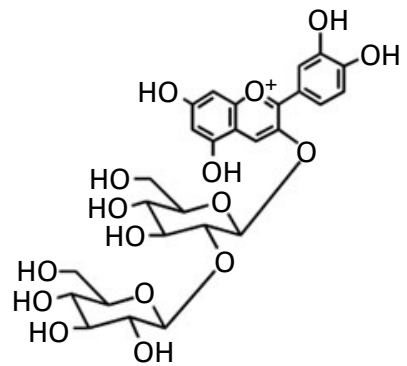

Cyanidin-3-O-sophoroside (Raspberry)

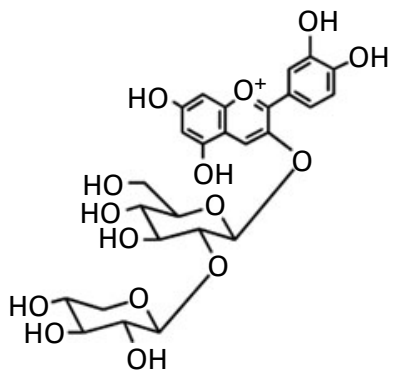

Cyanidin-3-O-sambubioside (Elderberry)

Fig. 2. Major anthocyanins in berries.

plasma and urine over a $24 \mathrm{~h}$ period. As flavonoid metabolites were and, indeed, still are rarely available, analysis almost invariably involved treatment of samples with mollusc glucuronidase/sulphatase preparations and subsequent quantification of the released aglycones by HPLC using either absorbance, fluorescence or electrochemical detection. Some more bioavailability studies have analysed samples directly by HPLC with tandem MS detection without recourse to enzyme hydrolysis. The availability of reference compounds enables specific metabolites to be identified by HPLC-MS ${ }^{2}$ and
$\mathrm{MS}^{3(33)}$. In the absence of standards, it is not possible to distinguish between isomers and ascertain the position of conjugating groups on the flavonoid skeleton. Nonetheless, a metabolite, which in reality is, say, pelargonidin-3-O-glucuronide, can be partially identified as a pelargonidin- $O$-glucuronide on the basis of its MS fragmentation pattern ${ }^{(7)}$. The use of MS in this way represents a powerful HPLC detection system as with low ng quantities of sample it provides structural information on analytes of interest, which is not obtained with other detectors. 
Quantification of partially identified metabolites by MS using consecutive reaction monitoring or selected ion monitoring is, of necessity, based on a calibration curve of a related compound, which in the instance cited above could be pelargonidin-3-O-glucoside as it is available from commercial sources. In such circumstances, as the slopes of the glucoside and glucuronide selected ion monitoring dose:response curves will not necessarily be identical, there is a potential source of error in the quantitative estimates and there is a view that quantitative estimates based on enzyme hydrolysis are, therefore, much more accurate. We do not share this opinion. The glucuronidase/sulphatase preparations contain a mixture of enzyme activities, and there can be a substantial batch-tobatch variation in their specificity ${ }^{(25)}$. There are no reports of flavonoid bioavailability studies using glucuronidase/ sulphatase preparations where information on the identity, number and quantity of the individual sulphate and glucuronide conjugates in the samples of interest has been obtained. As a consequence, there are no direct data on the efficiency with which the enzymes hydrolyse the individual metabolites and release the aglycone. This introduces a varying, unmeasured error factor. The accuracy of quantitative estimates based on the use of glucuronidase/sulphatase preparations is, therefore, probably no better, and possibly much worse, than those based on HPLC-consecutive reaction monitoring/ selected ion monitoring. The fact that enzyme hydrolysis results in very reproducible data is an irrelevance as reproducibility is a measure of precision, although it is frequently mistaken for accuracy ${ }^{(34)}$. These shortcomings of analyses based on enzyme hydrolysis apply to bioavailability studies with all dietary flavonoids, and it is interesting to note that the one publication on the subject to date reports that the use of enzyme hydrolysis results in an underestimation of isoflavone metabolites $^{(35)}$.

\section{Anthocyanins}

Anthocyanins, for people who eat berries and drink red wine on a routine basis, are major dietary components. Although there are exceptions, unlike other flavonoids that are absorbed and excreted, most anthocyanins do not appear to undergo extensive metabolism of the parent anthocyanidin to glucuronide, sulphate or methyl derivatives ${ }^{(15,36-39)}$. In feeding studies with human subjects and most animal test systems, typically approximately $<0.1 \%$ of the quantities ingested, and sometimes much less, have been detected in urine within $24 \mathrm{~h}$ of consumption, although higher recoveries have been reported after acute intake of raspberries by rats $(1.22 \%)^{(40)}$ and a bilberry extract by mice $(0.62-2.45 \%)^{(41)}$. The available data imply that the determinants of absorption and excretion are influenced not only by the nature of the sugar moiety but also by the structure of the anthocyanidin aglycone $^{(15,42)}$.

The complex array of information on anthocyanin bioavailability obtained with human and animal test systems has been reviewed by Prior \& $\mathrm{Wu}^{(43)}$. One of the reasons for the complicated picture that has emerged is that many feeds have involved berries or berry extracts containing several structurally diverse anthocyanins (Table 1). For instance, raspberries contain ten or more anthocyanins in the form of cyanidin- and pelargonidin-3- $O$-sugar conjugates ranging from mono- to 


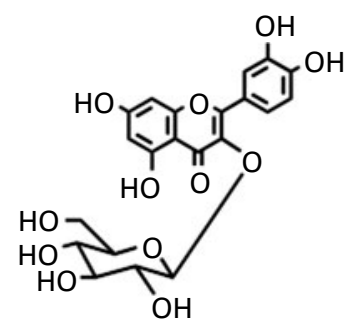

Quercetin-3-O-glucoside

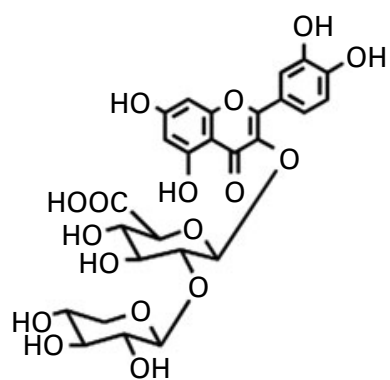

Quercetin-3-O-(2"-O-xylosyl)glucuronide<smiles></smiles>

Quercetin-3-O-galactoside

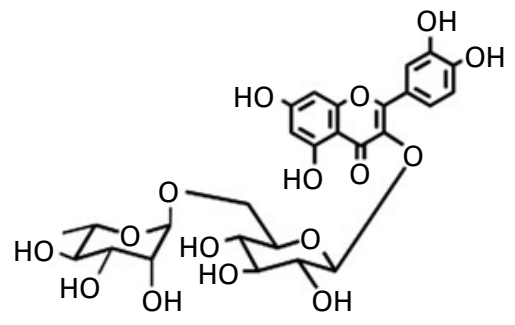

Quercetin-3-O-rutinoside<smiles></smiles>

Myricetin-3-O-glucoside<smiles>O=c1c(O)c(-c2cc(O)c(O)c(O)c2)oc2cc(O)cc(O)c12</smiles>

Myricetin-3-O-galactoside

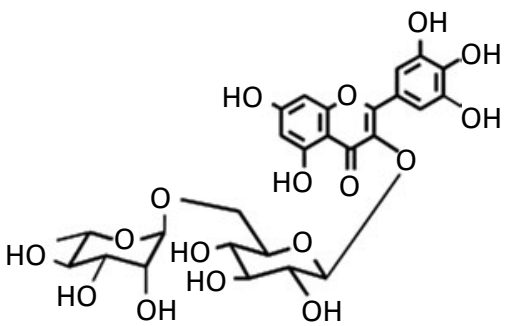

Myricetin-3-O-rutinoside

Fig. 3. Flavonols identified in berries.

trisaccharides, while blueberries contain more than fourteen anthocyanins, principally 3-O-glucosides, galactosides and arabinosides of cyanidin, delphinidin, petunidin and malvidin (Table 1). This makes the trace levels of complex anthocyanin profiles in plasma and urine exceedingly difficult, if not impossible to assess, in terms of absorption, excretion and potential phase I and phase II metabolism, especially when $3^{\prime}$-O-methylation can convert cyanidin to peonidin, and delphinidin to petunidin, and $5^{\prime}-O$-methylation converts petunidin to malvidin. Much simpler anthocyanin profiles are found in strawberries and blackberries, both of which contain one predominant anthocyanin, pelargonidin-3-O-glucoside in the former and cyanidin-3-O-glucoside in the latter (Table 1$)^{(44)}$. As a consequence, data on anthocyanins bioavailability after ingestion of these berries by human subjects are potentially more straightforward to interpret.

Strawberries and blackberries. In a recent human study, $200 \mathrm{~g}$ of strawberries containing $222 \mu \mathrm{mol}$ of pelargonidin-3$O$-glucoside and trace quantities of pelargonidin-3- $O$-rutinoside $(13 \mu \mathrm{mol})$ and cyanidin-3-O-glucoside $(6 \mu \mathrm{mol})$ were consumed after which plasma and urine were collected over a $24 \mathrm{~h}$ period $^{(7)}$. The plasma contained a pelargonidin- $O$-glucuronide along with non-quantifiable amounts of three other pelargonidin- $O$-glucuronides and pelargonidin-3- $O$-glucoside, the latter perhaps derived from removal of the $6^{\prime \prime}$-rhamnose moiety from pelargonidin-3-O-rutinoside. The main pelargonidin- $O$-glucuronide had a peak plasma concentration $\left(C_{\max }\right)$ of $274(\mathrm{SD} 24) \mathrm{nM}, 1 \cdot 1(\mathrm{SD} 0 \cdot 4) \mathrm{h}$ after ingestion $\left(T_{\max }\right)$ (Fig. 8), in keeping with small intestine absorption, and an elimination half-life of $2 \cdot 1$ (SD 0.7) h. All the plasma anthocyanins also appeared in urine along with small quantities of pelargonidin aglycone and a pelargonidin- $O$-sulphate. The pelargonidin$O$-glucuronide that was the main metabolite in plasma was by far the predominant component in urine accounting over $0-24 \mathrm{~h}$ for $1498 \mathrm{nmol}$ of a total of $1672 \mathrm{nmol}$ of anthocyanins excreted. This corresponds to $0.75 \%$ of pelargonidin-3-O-glucoside intake. There is, therefore, no evidence of substantive post-absorption metabolism before excretion.

In an earlier feeding study with strawberries, Felgines et $a l .{ }^{(45)}$ reported a urinary excretion equivalent to $1.8 \%$ of the $179 \mu \mathrm{mol}$ of ingested pelargonidin-3-O-glucoside, and this is similar to values obtained in a $15-60 \mu \mathrm{mol}$ dose study with strawberries by Carkeet et $a l .{ }^{(46)}$. These urinary recoveries are high for anthocyanins and suggest that pelargonidin-3- $O$-glucoside is absorbed more readily than other anthocyanins. In a separate human feeding study with $200 \mathrm{~g}$ 
<smiles>Oc1cc(O)c2c(c1)O[C@H](c1ccc(O)c(O)c1)[C@H](O)C2</smiles>

(-)-Epicatechin<smiles>Oc1cc(O)c2c(c1)O[C@H](c1ccc(O)c(O)c1)[C@H](O)C2</smiles>

(+)-Catechin<smiles>Oc1cc(O)c2c(c1)O[C@H](c1ccc(O)c(O)c1)[C@H](O)[C@H]2c1c(O)cc(O)c2c1O[C@H](c1ccc(O)c(O)c1)[C@H](O)C2</smiles>

Proanthocyanidin $\mathrm{B}_{2}$ dimer<smiles>Oc1cc(O)c2c(c1)O[C@H](c1ccc(O)c(O)c1)[C@H](O)[C@H]2c1c(O)cc2c(c1O)C[C@@H](O)[C@H](c1ccc(O)c(O)c1)O2</smiles>

Proanthocyanidin $\mathrm{B}_{5}$ dimer

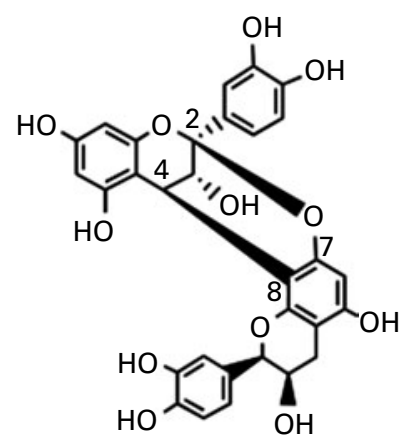

Proanthocyanidin $\mathrm{A}_{2}$ dimer

Fig. 4. Flavan-3-ol monomers and procyanidins identified in berries.

of blackberries containing $960 \mu \mathrm{mol}$ of cyanidin-3-O-glucoside, twelve anthocyanins were excreted including unmetabolised cyanidin-3-O-glucoside, a cyanidin- $O$-glucuronide and a peonidin- $O$-glucuronide in quantities equivalent to $0.16 \%$ of intake $^{(47)}$. This suggests that the $3^{\prime}$-hydroxy anthocyanin, pelargonidin-3-O-glucoside, while it is metabolised to fewer products, may be absorbed more readily than its $3^{\prime}, 4^{\prime}$-dihydroxy analogue, cyanidin-3-O-glucoside. However, the high cyanidin-3-O-glucoside content of the blackberry supplement may have had an impact on absorption and/or excretion. In the circumstances, it would be of interest to carry out a feeding study and to determine not only the urine but also the plasma anthocyanin profile after ingestion of blackberries and strawberries containing similar quantities of anthocyanins.

Blueberries and blackcurrants. Ingestion of a blueberry extract, containing $1.2 \mathrm{~g}$ of a complex array of anthocyanins, with a high-fat meal resulted in an increase in serum oxygen radical absorbance capacity, but not trolox equivalent antioxidant capacity, antioxidant activity 1 and $4 \mathrm{~h}$ after intake by human volunteers. This was associated with the appearance of trace levels of blueberry anthocyanins in serum, but as they accounted for only $0.002-0.003 \%$ of intake, it appears unlikely that the anthocyanins themselves were directly responsible for the increase in antioxidant status ${ }^{(48,49)}$. In a separate human study, following consumption of a blueberry extract containing $439 \mathrm{mg}$ of anthocyanins, trace quantities of unmetabolised anthocyanins corresponding to $0.02 \%$ of intake were detected in urine collected over a $7 \mathrm{~h}$ post-ingestion period ${ }^{(15)}$. In another study, Wu et al. ${ }^{(50)}$ fed $690 \mathrm{mg}$ of blueberry anthocyanins to 60- to 70-year-old women, and total urinary excretion during the first $6 \mathrm{~h}$ after consumption was $23.2 \mu \mathrm{g}$, which is equivalent to $0.004 \%$ of intake.

Human urinary excretion of blackcurrant anthocyanins, such as those from blueberry, is low with approximately $0.06 \%$ of intake being recovered as unmetabolised native anthocyanins $^{(15)}$. A similar recovery level in urine was

Table 2. Concentration of flavan-3-ol monomers, dimers and trimers and total proanthocyanidins in berries (Mean values (mg/kg fresh wt) and standard deviations)

\begin{tabular}{|c|c|c|c|c|c|c|c|c|c|}
\hline \multirow[b]{2}{*}{ Berry } & \multicolumn{2}{|c|}{ Monomers } & \multicolumn{2}{|c|}{ Dimers } & \multicolumn{2}{|c|}{ Trimers } & \multicolumn{2}{|c|}{ Total PA } & \multirow[b]{2}{*}{ References } \\
\hline & Mean & SD & Mean & SD & Mean & SD & Mean & SD & \\
\hline Cranberry & 73 & 15 & 259 & 61 & 189 & 13 & 4188 & 750 & $\mathrm{Gu}$ et al. ${ }^{(20)}$ \\
\hline Blueberry & 40 & 15 & 72 & 18 & 54 & 12 & 1798 & 508 & Gu et al. ${ }^{(20)}$ \\
\hline Blackcurrant & 9 & 2 & 29 & 4 & 30 & 3 & 1478 & 280 & $\mathrm{Gu}$ et al. ${ }^{(20)}$ \\
\hline Strawberry & 42 & 7 & 65 & 13 & 65 & 12 & 1450 & 250 & $\mathrm{Gu}$ et al. ${ }^{(20)}$ \\
\hline Redcurrant & 13 & - & 20 & - & 15 & - & 608 & - & Wu et al. ${ }^{(5)}$ \\
\hline Red raspberry & 44 & 34 & 115 & 100 & 57 & $5 \cdot 7$ & 302 & 230 & $\mathrm{Gu}$ et al. ${ }^{(20)}$ \\
\hline Blackberry & 37 & 22 & 67 & 29 & 36 & 19 & 270 & 170 & $\mathrm{Gu}$ et al. ${ }^{(20)}$ \\
\hline
\end{tabular}

PA, proanthocyanidins. 
<smiles>O=c1oc2c3c(c4c(oc3=O)c(O)cc1-4)C=C2O</smiles>

Ellagic acid<smiles>O=C(O)c1cc(O)c(O)c(O)c1</smiles>

Gallic acid

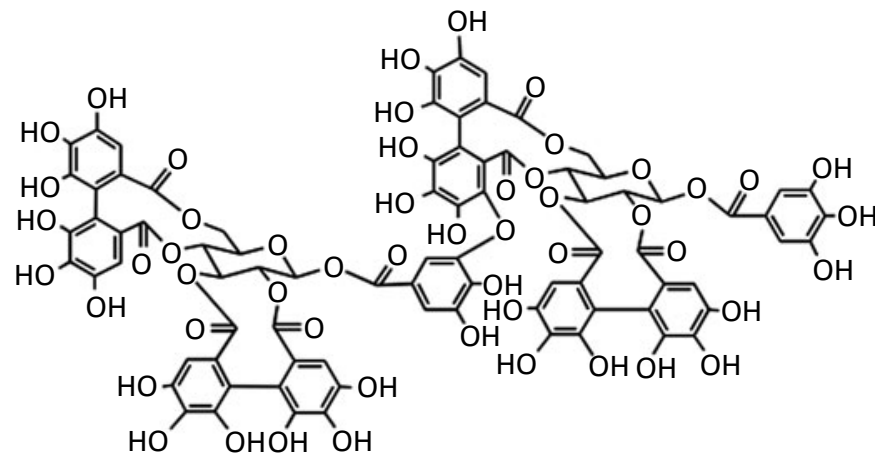

Sanguiin $\mathrm{H}-6$

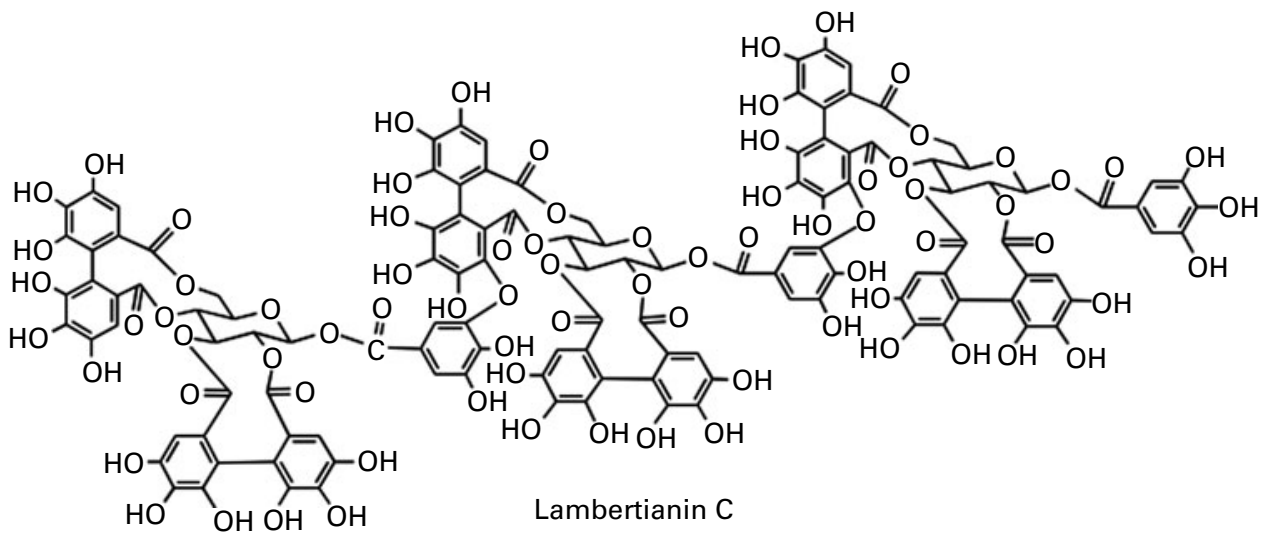

Fig. 5. Gallic acid, ellagic acid and the raspberry ellagitannins sanguiin $\mathrm{H}-6$ and lambertianin $\mathrm{C}$.

reported with weanling pigs, but in this case, approximately $25 \%$ of the anthocyanins were methyl and/or glucuronide metabolites $^{(42)}$.

Stability of anthocyanins. A point of note is that anthocyanins are readily distinguished from other flavonoids as they undergo rearrangements in response to $\mathrm{pH}$. The red flavylium cation predominates at $\mathrm{pH} 1-3$, but as the $\mathrm{pH}$ increases to 4 and above, the colourless carbinol pseudobase is the major component along with smaller amounts of the colourless chalcone pseudobase and the blue quinoidal base (Fig. 9) ${ }^{(51)}$. Anthocyanins are traditionally extracted and analysed in acidic medium, as the red flavylium cation is the most stable form. However, it is not known what forms predominate in vivo. The limited available experimental evidence indicates that in the acidic conditions that prevail in the stomach, anthocyanins are in the red flavylium form, but once they enter the

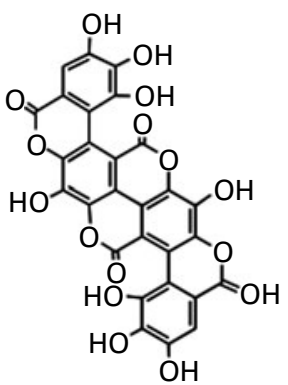

Gallagic acid

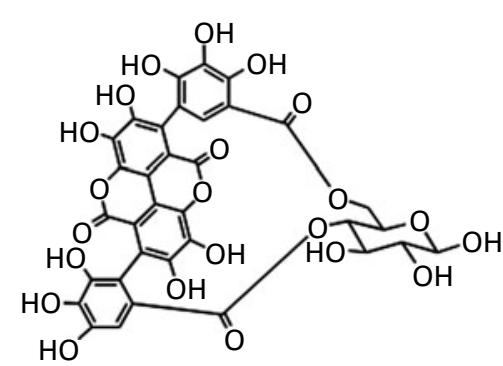

Punicalin

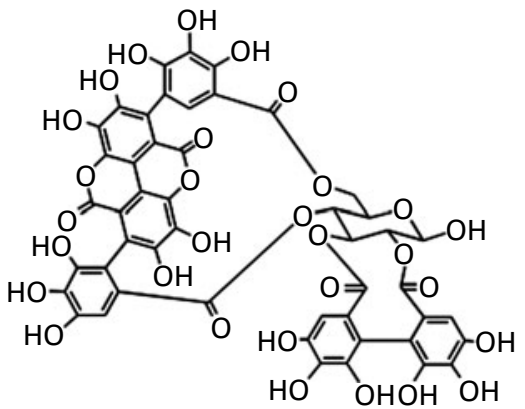

Punicalagin

Fig. 6. Pomegranates contain gallagic acid and the ellagitannins punicalin and punicalagin. 


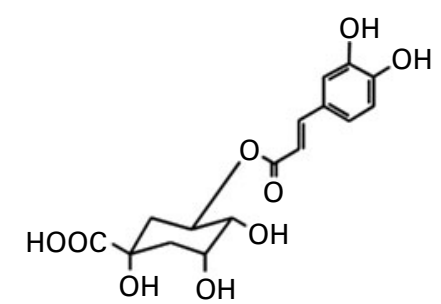

5-O-Caffeoylquinic acid<smiles>O=C(CCc1ccc(O)cc1)OC(C(=O)O)C(O)C(=O)O</smiles>

Coutaric acid<smiles>O=C(CCc1ccc(O)c(O)c1)OC(C(=O)O)C(O)C(=O)O</smiles>

Caftaric acid
Fig. 7. The chlorogenic acid 5-O-caffeoylquinic acid and the hydroxycinnamate-tartaric acid conjugates, coutaric acid and caftaric acid.

higher $\mathrm{pH}$ of the small intestine, the carbinol pseudobase is likely to predominate. It could be that the colourless carbinol pseudobase is the main form in the small intestine where it undergoes limited absorption, possibly being metabolised to conjugates that are overlooked because they cannot be converted to red flavylium forms before the eventual analysis. It is also possible that significant amounts of the carbinol pseudobase as well as the parent anthocyanin pass into the large intestine where degradation to phenolic acid occurs due to the action of colonic bacteria. As a further complication, anthocyanins also breakdown to phenolic acid and aldehyde constituents when subjected to simulated physiological conditions and during sample processing before analysis. In this regard, experiments with pelargonidin, cyanidin and delphinidin showed that increased B-ring hydroxylation is associated with decreased stability ${ }^{(52)}$.

\section{Flavan-3-ols}

Flavan-3-ol monomers. Although berries have been shown to contain $(-)$-epicatechin and $(+)$ - catechin $^{(53,54)}$, they are relatively minor constituents and occur in much more

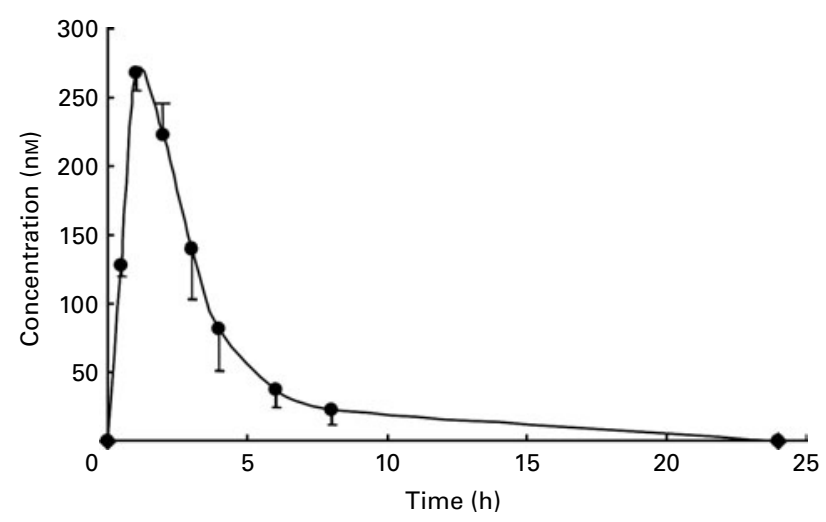

Fig. 8. Concentration of a pelargonidin-O-glucuronide in the plasma of human subjects $0-24 \mathrm{~h}$ after the ingestion of $200 \mathrm{~g}$ of strawberries containing $222 \mu \mathrm{mol}$ of pelargonidin-3-O-glucoside. Data expressed as mean values in $\mathrm{nM}$ with their standard error are depicted by vertical bars $(n 8)^{(7)}$. substantial quantities in green tea, which, unlike berries, also contains (epi)gallocatechin and (epi)gallocatechn-3-O-gallates. Cocoa products also contain $(-)$-epicatechin and $(+)-$ catechin along with procyanidins, which can be sizable constituents in berries (Table 2). As a consequence, although there is information on the bioavailability of these compounds, it has been obtained in feeding studies with green tea and cocoa rather than berries.

In a recent bioavailability study, a drink made with $10 \mathrm{~g}$ of cocoa powder and $250 \mathrm{ml}$ of hot water was consumed by human volunteers with plasma and urine being collected over the ensuing $24 \mathrm{~h}$ period $^{(55)}$. The drink contained $22.3 \mu \mathrm{mol}$ of catechin, almost all of it as the less bioavailable $(-)$-isomer ${ }^{(56)}$, and $23.0 \mu \mathrm{mol}$ of $(-)$-epicatechin along with $70 \mathrm{mg}$ of procyanidins, and after consumption, plasma and urine were collected over a $24 \mathrm{~h}$ period for analysis by HPLC-MS ${ }^{2}$. Two flavan-3-ol metabolites were detected in plasma, an $O$-methyl-(epi)catechin- $O$-sulphate and a (epi)catechin- $O$-sulphate. Both had a $C_{\max }$ below $100 \mathrm{~nm}$ and a $T_{\max }$ of $<1.5 \mathrm{~h}$ (Fig. 10), indicative of absorption in the small rather than the large intestine. In feeds with green tea containing higher levels of the flavan-3-ol monomers, the same (epi)catechin metabolites were detected along with a lower concentration of an (epi)catechin- $O$-glucuronide, possibly $(-)$-epicatechin- $3^{\prime}-O$-glucuronide ${ }^{(57)}$. In the cocoa study, the two sulphated flavan-3-ols were also the main metabolites in urine, which, in addition, contained smaller quantities of an (epi)catechin- $O$-glucuronide and an additional (epi)catechin$O$-sulphate. The amount of flavan-3-ol metabolites excreted in urine over the $0-24 \mathrm{~h}$ collection period was 7.7 (SD $0 \cdot 8) \mu \mathrm{mol}$. When calculated as a percentage of cocoa flavan3 -ols ingested, this is equivalent to 18.3 (SD 1.9) \% of intake. This figure is probably nearer $30 \%$ because almost half of the flavan-3-ol intake was (-)-catechin which has reduced bioavailability ${ }^{(56)}$, and as such is comparable with urinary (epi)catechin excretion levels obtained after the ingestion of cocoa $^{(58)}$ and green tea ${ }^{(57,59)}$. Despite this high level of excretion, indicative of substantial absorption into the circulatory system, the accompanying combined plasma $C_{\max }$ value for the two sulphated cocoa flavan-3-ol metabolites was only 143 (SD 8) nM. This suggests that following absorption, the (epi)catechin metabolites are a state of flux and are rapidly turned over in the circulatory system and, rather than accumulating, are excreted via the kidneys. In the circumstances, urinary excretion provides a more realistic assessment of absorption than figures from plasma $C_{\max }$, but as this does not include the possibility of metabolites being sequestered in body tissues, this too is theoretically an under estimate of absorption, but to what degree remains to be determined. However, the fact that tissue sequestration has yet to be convincingly demonstrated suggests that it can only be at low levels, if at all.

Studies with rats have led to suggestions that flavan-3-ol monomers may be removed from the bloodstream in the liver and returned to the small intestine in the bile ${ }^{(60,61)}$. To what extent enterohepatic transport of flavan-3-ol metabolites occurs in human subjects remains to be established.

There are claims in the literature that flavan-3-ols are poorly bioavailable because of instability under digestive conditions with $>80 \%$ losses being observed with in vitro digestion models simulating gastric and small intestine conditions ${ }^{(62-65)}$. 


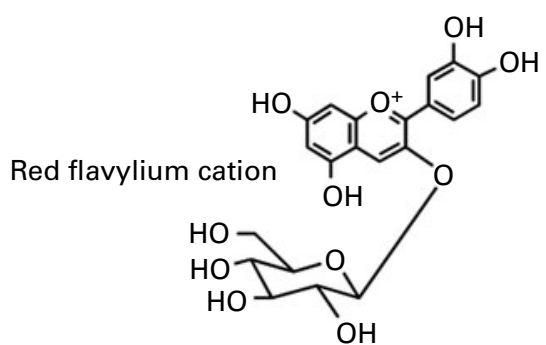

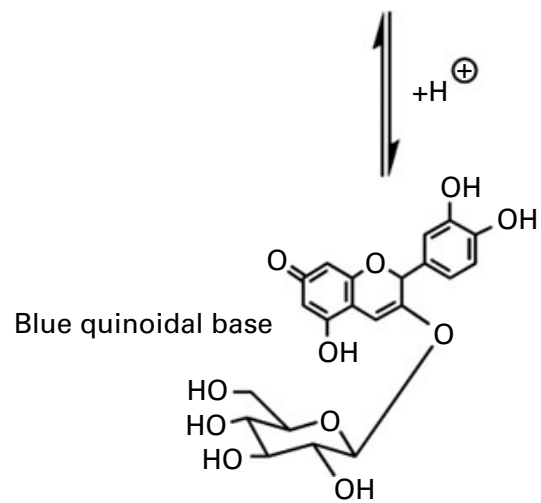

Fig. 9. Effect of $\mathrm{pH}$ on the structure of anthocyanins.

It is clear that the data obtained in these investigations do not accurately reflect the in vivo fate of flavan-3-ols following ingestion, as they are at variance with the high urinary excretion observed in cocoa and green tea feeding studies $^{(32,57)}$, and also with the substantial recoveries of flavan-3-ols in ileal fluid after the consumption of a green tea infusion and Polyphenon E, a green tea extract, by human subjects with an ileostomy ${ }^{(59,66)}$.

Procyanidins. Procyanidins are major components in the human diet because of their widespread occurrence in fruits, berries nuts, beans, cocoa-based products, wine and beer ${ }^{(20)}$. In vivo their consumption has been implicated in improved antioxidant status ${ }^{(67)}$, decreased DNA damage in human subjects $^{(68)}$, reduced development of aortic atherosclerosis ${ }^{(69)}$ and delayed tumour production ${ }^{(70)}$ in animal test systems. Because of these and other biological effects of procyanidins ${ }^{(71)}$, derived principally from the ingestion of grape seed extracts or consumption of cocoa-derived food stuffs rather than berries, information on the bioavailability of procyanidins and the compounds responsible for these effects in vivo is of importance.

There are numerous feeding studies with animals and human subjects indicating that polymeric procyanidins are not absorbed ${ }^{(72)}$. Most pass unaltered to the large intestine where they are catabolised by the colonic microflora yielding a diversity of phenolic acids ${ }^{(32,73-75)}$ including 3-(3-hydroxyphenyl)propionic acid and 4-O-methyl-gallic $\operatorname{acid}^{(76)}$, which are absorbed into the circulatory system and excreted in urine. There is one report based on data obtained in an in vitro model of gastrointestinal conditions that procyanidins degrade yielding more readily absorbable flavan-3-ol monomers ${ }^{(77)}$. Subsequent studies have not supported this conclusion $^{(78-80)}$. There are two reports of minor quantities of procyanidin dimers $B_{1}$ and $B_{2}$ being detected in human plasma after the respective consumption of a grape seed extract $^{(81)}$ and a flavan-3-ol-rich cocoa ${ }^{(82)}$. In the latter
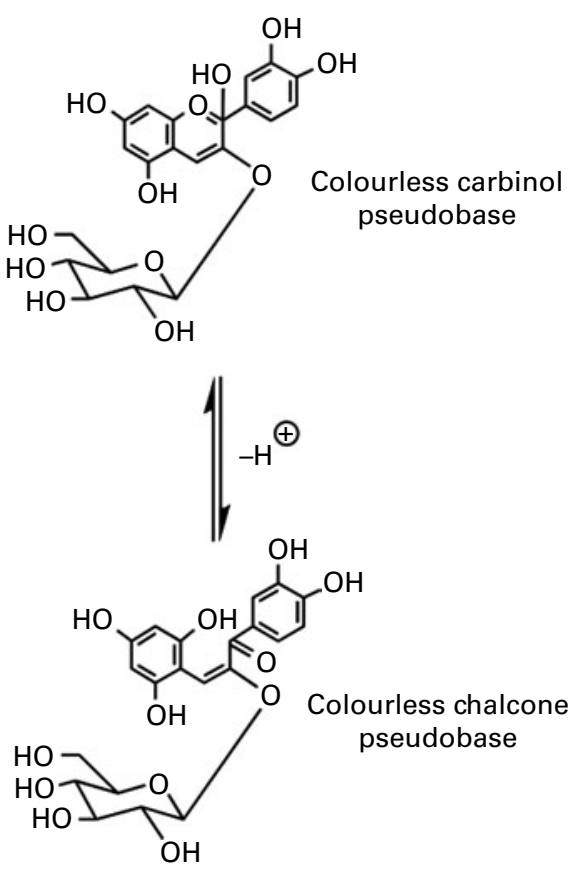

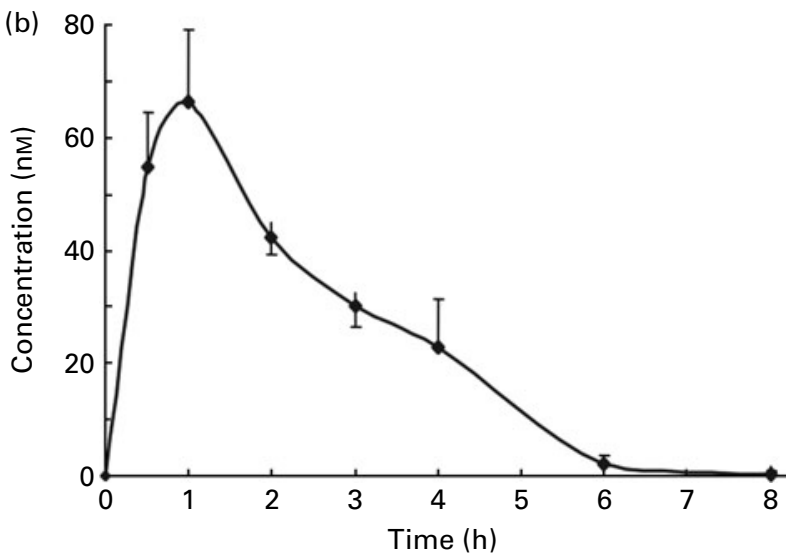

Fig. 10. Concentrations of (a) (epi)catechin- $O$-sulphate and (b) $O$-methyl(epi)catechin- $O$-sulphate in the plasma of human subjects $0-8 \mathrm{~h}$ after the ingestion of $250 \mathrm{ml}$ of a cocoa beverage containing $45 \mu \mathrm{mol}$ of (epi)catechins. Data expressed as mean values in nM with their standard error depicted are by vertical bars $(n 9)$. Note that no flavan-3-ols or their metabolites were detected in plasma collected $24 \mathrm{~h}$ after ingestion of the cocoa ${ }^{(55)}$ 
study, the levels of the $\mathrm{B}_{2}$ dimer in plasma were approximately 100-fold lower than those of flavan-3-ols monomers.

The biological effects of procyanidins are generally attributed to their more readily absorbed colonic breakdown products, the phenolic acids, although there is a lack of detailed study in this area ${ }^{(78)}$. There is, however, a dissenting view as trace levels of procyanidins, in contrast to (-)-catechin and (+)-epicatechin, inhibit platelet aggregation in vitro and suppress the synthesis of the vasoconstriction peptide, endothelin-1, by cultured endothelial cells ${ }^{(83)}$. Supporting this view is a study in which individual procyandins were fed to rats after which dimers through to pentamers were detected in plasma, which had been extracted with $8 \mathrm{M}$-urea, rather than the more traditional methanol/acetonitrile. This, as it was proposed, prevented the irreversible binding of procyanidins to plasma proteins ${ }^{(84)}$. The procyanidins were, however, administered by gavage at an extremely high dose, $1 \mathrm{~g} / \mathrm{kg}$ body weight, and it remains to be determined whether procyanidins can be similarly detected in urea-extracted plasma after the ingestion of more nutritionally relevant doses.

\section{Ellagitannins}

Studies into the bioavailability of ellagitannins following ingestion by human subjects have been carried out mainly with pomegranate, which contains punicalin and punicalagins (Fig. 6) ${ }^{(85-87)}$. However, the fate of ellagitannins in strawberries, raspberries, walnuts and oak-aged wines has also been investigated $^{(88)}$.

After drinking a pomegranate juice containing $318 \mathrm{mg}$ of punicalagins, ellagic acid was detected in plasma with a $C_{\max }$ of $60 \mathrm{~nm}$ at a $T_{\max }$ of $0.98 \mathrm{~h}$ suggesting acid hydrolysis of at least some of the ellagitannins releasing free ellagic acid, which is absorbed directly from the stomach or the proximal small intestine ${ }^{(86)}$. Also detected in the plasma of<smiles>O=c1oc2cc(O)ccc2c2ccc(O)cc12</smiles>

Urolithin A

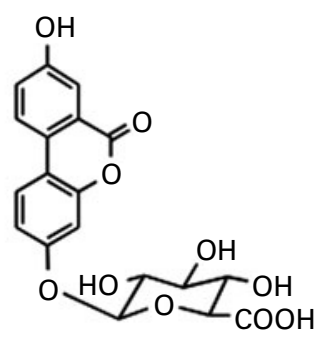

Urolithin A-3-O-glucuronide<smiles>O=c1oc2cc(O)ccc2c2cc(O)c(O)cc12</smiles>

Urolithin C
Urolithin D<smiles>O=c1oc2c(O)c(O)ccc2c2cc(O)c(O)cc12</smiles><smiles>O=c1oc2cc(O)ccc2c2ccccc12</smiles>

Urolithin B

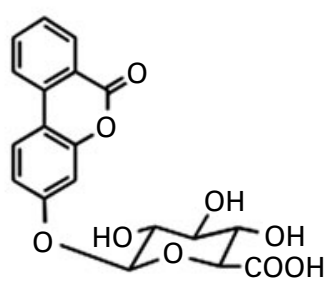

Urolithin B-3-O-glucuronide

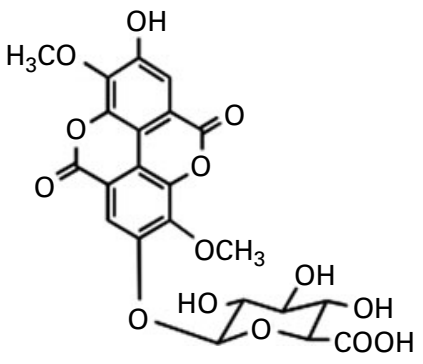

3,8-O-Dimethylellagic acid-2-O-glucuronide

Fig. 11. Structures of urolithins and related compounds. 
producing urolithin $\mathrm{D}$, urolithin $\mathrm{C}$, urolithin $\mathrm{A}$ and urolithin B. These urolithins are absorbed preferentially as their lipophilicity increases, with plasma containing mainly urolithin A-3$O$-glucuronide and urolithin B-3-O-glucuronide with traces of an urolithin $\mathrm{C}$ - $\mathrm{O}$-glucuronide and 3,8-O-dimethylellagic acid2-O-glucuronide (Fig. 11). The urolithin $\mathrm{A}$ and $\mathrm{C}$ glucuronides were the major components in urine. Among the twenty-six conjugated metabolites detected in bile were substantial quantities of urolithin A, C and D derivatives as well as glucuronides and methyl glucuronides of ellagic acid. This indicates extensive hepatic metabolism and active enterohepatic circulation, and also explains the persistence of urinary urolithin metabolites observed in the human studies. No ellagitannins or their metabolites were detected in body tissues outside the gastrointestinal tract, which is interesting as the meat and fat of Iberian pigs fed on acorns are resistant to rancidity ${ }^{(89)}$. Perhaps this may be attributable to other potential ellagitannin colonic breakdown products such as phenolic acids, which have yet to be investigated.

\section{Other flavonoids}

Berries also contain a variety of mono-, di- and trisaccharide flavonol conjugates (Table 1), none in especially high concentrations, and there are few, if any, human studies on the bioavailability of berry flavonols. Investigations with other products, such as onions that contain substantial amounts of flavonols, indicate that quercetin- $O$-glucosides are hydrolysed by lactase phloridizin hydrolase and/or cytosolic $\beta$-glucosidase in the small intestine, and that the released aglycone is subjected to the action of sulphotransferases, UDP-glucuronosyltransferases and catechol- $O$-methyltransferases before entry into the circulatory system with sub $\mu \mathrm{M} C_{\max }$ concentrations of a number of metabolites including quercetin- $3^{\prime}-O$-sulphate, quercetin-3-O-glucuronide and isorhmanetin-3-O-glucuronide appearing in plasma with a $T_{\max }$ of $<1.0 \mathrm{~h}$ (Fig. 12). The profile of urinary metabolites is markedly different to that in plasma, indicating that phase II metabolism is operative. Overall excretion of metabolites is equivalent to approximately $4 \%$ of the $275 \mu \mathrm{mol}$ intake of flavonol- $O$-glucosides ${ }^{(33)}$.

Feeding studies with tomato juice containing $176 \mu \mathrm{mol}$ quercetin-3-O-rutinoside have shown that quercetin-3-O-glucuronide and isorhamnetin-3-O-glucuronide appear in plasma with a $T_{\max }$ of approximately $5 \mathrm{~h}$ and low $\mathrm{nM} C_{\max }$ values approximately 25-fold lower than in the onion study (Fig. 13) ${ }^{(29)}$. The extended $C_{\max }$ is in keeping with absorption in the large intestine rather than the small intestine. The absence of quercetin- $3^{\prime}-O$-sulphate in plasma, which was the main metabolite to accumulate in the onion feed, suggests that sulphation of quercetin is restricted to the small intestine. The excretion of metabolites, where there was also an absence of sulphates, after ingestion of the tomato juice ranged from 0.02 to $2.8 \%$ of quercetin-3-O-rutinoside intake, which probably reflects marked variations in the colonic microflora of the individual volunteers. Urine collected $0-24 \mathrm{~h}$ after tomato juice intake also contained 3,4-dihydroxyphenylacetic acid, 3-hydroxyphenylacetic acid and 3-methoxy-4-hydroxyphenylacetic acid in amounts equivalent to $22 \%$ of quercetin-3-Orutinoside intake. These phenolic acids probably originate from colonic bacteria-mediated deglycosylation of the rutinoside and ring fission of the released quercetin followed
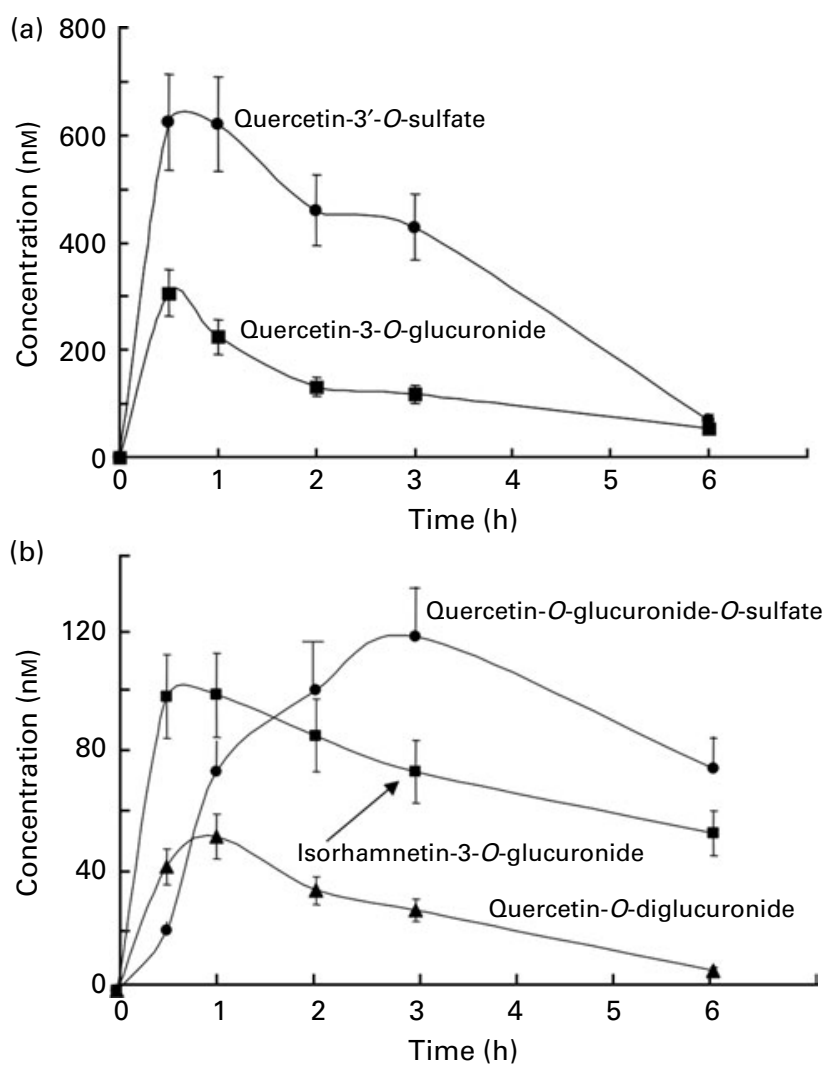

Fig. 12. Concentration of (a) quercetin- $3^{\prime}-O$-sulphate, quercetin-3-O-glucuronide, (b) isorhamnetin-3-O-glucuronide and other quercetin-derived metabolites in plasma from human volunteers collected $0-6 \mathrm{~h}$ after the ingestion of $270 \mathrm{~g}$ of lightly fried onions containing $143 \mu \mathrm{mol}$ of quercetin- $4^{\prime}-O$-glucoside and $107 \mu \mathrm{mol}$ of quercetin-3,4'-O-diglucoside along with trace levels of other flavonol-O-glucosides. Data expressed as mean values in nM with their standard error are depicted are by vertical bars $(n 6)$. Note that these metabolites were not detected in plasma collected $24 \mathrm{~h}$ after supplementation ${ }^{(33)}$.

by the conversions illustrated in Fig. 14, some of which appear to be a consequence of phase II metabolism in the liver before excretion. Confirmation of large intestine absorption was obtained by feeding the tomato juice to volunteers with an ileostomy. Unlike the healthy subjects with a functioning colon, neither plasma nor urinary metabolites/catabolites were detected, and ileal fluid contained $86 \%$ of the ingested quercetin-3- $O$-rutinoside ${ }^{(29)}$.

Although not found in berries, hesperetin-7-O-rutinoside, a flavanone conjugate, is consumed widely by the general public

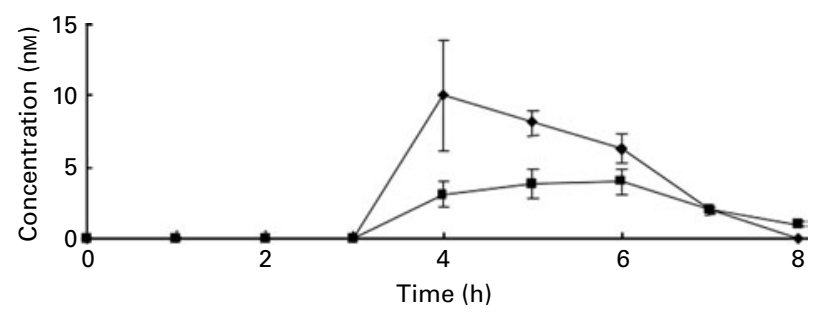

Fig. 13. Concentration of quercetin-3-O-glucuronide $(-\bullet-)$ and isorhamnetin-3-O-glucuronide (- - ) in the plasma of human subjects $0-8 \mathrm{~h}$ after the consumption of tomato juice containing $176 \mu \mathrm{mol}$ of quercetin-3-O-rutinoside. Data expressed as mean values in nM with their standard error are depicted by vertical bars $(n 6)$. Note that neither metabolite was detected in plasma collected $24 \mathrm{~h}$ after supplementation ${ }^{(29)}$. 


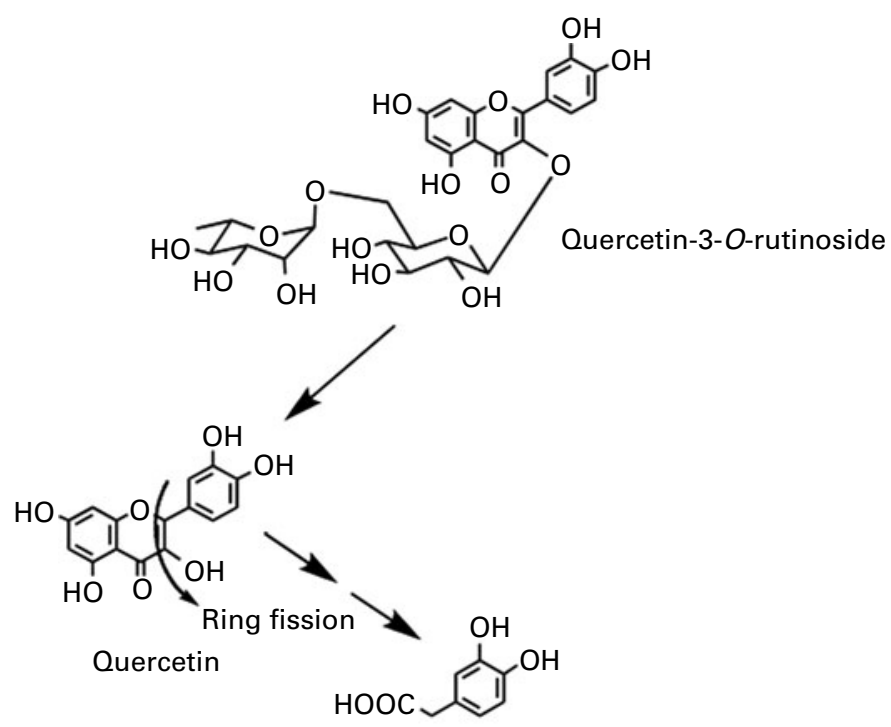

3,4-Dihydroxyphenylacetic acid

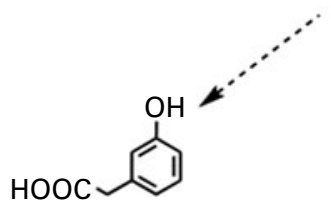

3-Hydroxyphenylacetic acid

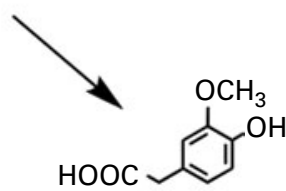

3-Methoxy-4-hydroxyphenylacetic acid

Fig. 14. Proposed pathway for the bacterial-mediated catabolism of quercetin-3-O-rutinoside in the large intestine resulting in the production of $3,4-$ dihydroxyphenylacetic acid and smaller quantities of 3-hydroxyphenylacetic acid with the subsequent hepatic conversion of 3,4-dihydroxyphenylacetic acid to 3-methoxy-4-hydroxyphenylacetic acid before urinary excretion. $--\rightarrow$, minor pathway ${ }^{(29)}$.

because of its occurrence in citrus products. Following ingestion of orange juice containing $168 \mu \mathrm{mol}$ of hesperetin-7- $O$ rutinoside, hesperetin-7- $O$-glucuonide and an unassigned hesperetin- $O$-glucuronide appeared in plasma with a combined $C_{\max }$ of $922 \mathrm{~nm}$ and a $T_{\max }$ of $4.4 \mathrm{~h}$ (Fig. 15) ${ }^{(90)}$. Like the quercetin-3-O-rutinoside feed, the $T_{\max }$ implies absorption in the large intestine, but the $C_{\max }$ is 50 -fold higher than that of the quercetin metabolites. Hesperetin metabolite excretion in urine corresponded to $6.5 \%$ of the ingested hesperetin-7-Orutinoside. Overall, the data suggest that hesperetin-7-O-rutinoside is absorbed in the large intestine more effectively than quercetin-3-O-rutinoside. This may be a consequence of the hesperetin-7- $O$-rutinoside being converted to glucuronides more efficiently than quercetin-3- $O$-rutinoside, arguably because the aglycone is less prone to degradation by the colonic microflora.

Manach et al. ${ }^{(32)}$ provide additional information on the bioavailability of other flavonoids and related compounds, while more recent data on apple dihydrochalcones, soya isoflavones, and green tea (epi)gallocatechins and their 3-O-gallate derivatives, none of which occur in berries, are reviewed by Crozier et al. ${ }^{(23)}$.

\section{Matrix effects}

Although flavonoids and related compounds are typically consumed as part of a meal, there is surprisingly little information on how their bioavailability is affected by the other components in the diet. The limited data that are available, some of them obtained with berries, indicate that in many instances, simultaneous intakes with foods can affect the absorption and excretion of flavonoids.

It has been shown in a study with both rats and human subjects that phytic acid (myo-inositol hexaphosphate), a component of hulls of nuts, seeds and grain ${ }^{(91)}$, increases the bioavailability of blackcurrant anthocyanins ${ }^{(92)}$. Urinary recovery of the anthocyanins from rats was enhanced 5.8fold by co-ingestion with a $1 \%$ solution of phytic acid, which reduced gastrointestinal mobility and slowed the passage of the anthocyanins through the stomach, duodenum and jejunum, presumably thereby providing a longer time frame for the absorption of anthocyanins. Human plasma and urinary anthocyanin levels were also enhanced by phytic acid. The peak excretion was delayed until $4-8 \mathrm{~h}$ post-ingestion, and the recovery of anthocyanins increased $4 \cdot 5$-fold.

Walton et al. ${ }^{(93)}$ fed male pigs blackcurrant anthocyanins at a dose of $100 \mathrm{mg} / \mathrm{kg}$ body weight with (1) sugar and water, (2) a cereal (Weet-Bix), milk and sugar and (3) Weet-Bix, milk, sugar and quercetin-3-O-rutinoside $(93 \mathrm{mg} / \mathrm{kg})$, after which plasma was collected at intervals over an $8 \mathrm{~h}$ period. The main anthocyanins in the extract fed to the pigs were delphinidin-3-O-rutinoside and cyanidin-3- $O$-rutinoside with smaller amounts of delphinidin-3-O-glucoside and cyanidin-3-O-glucoside. The rutinosides were detected in plasma along with large amounts of two putative metabolites seemingly derived from delphinidin-3-O-glucoside and cyanidin-3-O-glucoside. As shown in Table 3, the addition of the cereal and milk to the matrix did not affect the anthocyanin plasma $C_{\max }$ or 


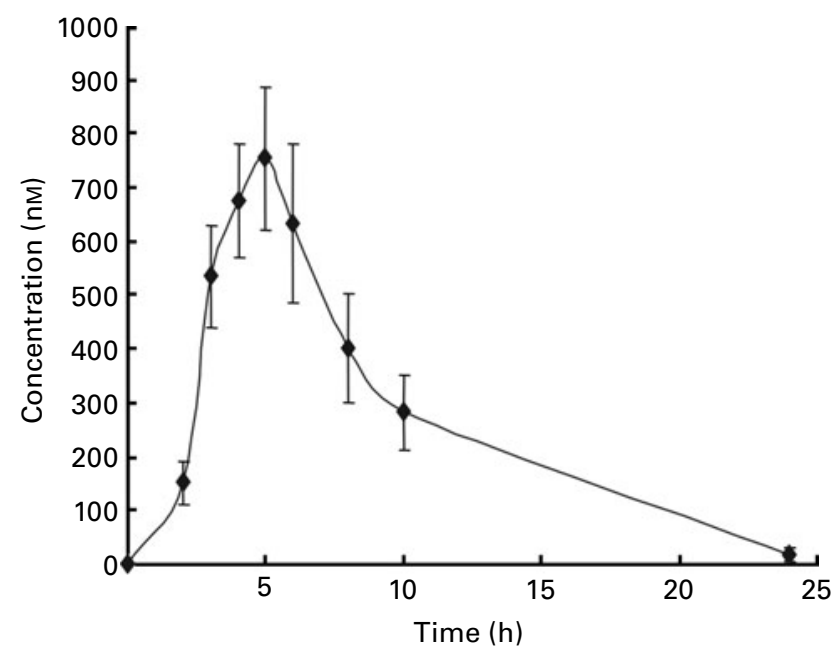

Fig. 15. Combined concentration of hesperetin-7-O-glucuronide and an unassigned hesperetin-O-glucuronide in the plasma of human subjects $0-24 \mathrm{~h}$ after ingesting $250 \mathrm{ml}$ of orange juice containing $168 \mu \mathrm{mol}$ of hesperetin7-O-rutinoside. Data expressed as mean values in $\mathrm{nm}$ with their standard error are depicted by vertical bars $(n 8)^{(90)}$.

$0-8 \mathrm{~h}$ area under the curve values, but it did extend $T_{\max }$ from 2 to $4 \mathrm{~h}$. The presence of quercetin-3-O-rutinoside along with the cereal and milk did not impact on the anthocyanin pharmacokinetic profile, indicating that there was no apparent competition for absorption between the anthocyanin rutinosides and glucosides and the flavonol rutinoside. The ferric reducing ability/power antioxidant capacity of the plasma increased significantly $8 \mathrm{~h}$ after the blackcurrant anthocyanin intake, at which point plasma anthocyanin levels had declined substantially from their $C_{\max }$ values. This suggests that other components rather than the anthocyanins themselves were responsible for the rise in antioxidant capacity.

There is also a report on a study in which blackcurrant anthocyanins were fed to rats by gavage at a dose of $250 \mathrm{mg} / \mathrm{kg}$ in acidified water with and without oatmeal ${ }^{(94)}$. The native blackcurrant 3-O-glucosides and rutinosides of delphinidin and cyanidin appeared in plasma and were also present in urine along with several additional, partially identified methylated and diglucuronide metabolites. The oatmeal significantly reduced the anthocyanin plasma $C_{\max }$ from

Table 3. Pharmacokinetic parameters of anthocyanins in pig plasma after a single oral dose of $100 \mathrm{mg}$ of blackcurrant anthocyanins $/ \mathrm{kg}$ body weight ${ }^{(93)}$

(Mean values and standard deviations)

\begin{tabular}{|c|c|c|c|c|c|}
\hline \multirow{2}{*}{$\begin{array}{l}\text { Additions to } \\
\text { anthocyanin diet }\end{array}$} & \multicolumn{2}{|c|}{$C_{\max }(\mu \mathrm{g} / \mathrm{ml})$} & \multirow[b]{2}{*}{$T_{\max }(\mathrm{h})$} & \multicolumn{2}{|c|}{$\begin{array}{c}0-8 \mathrm{~h} \mathrm{AUC} \\
(\mu \mathrm{g} / \mathrm{h} \text { per } \mathrm{ml})\end{array}$} \\
\hline & Mean & SD & & Mean & SD \\
\hline Sugar and water & 0.08 & 0.01 & 2 & 0.49 & 0.06 \\
\hline $\begin{array}{l}\text { Cereal, milk and } \\
\text { sugar }\end{array}$ & 0.09 & 0.01 & 4 & 0.54 & 0.05 \\
\hline $\begin{array}{l}\text { Cereal, milk, sugar } \\
\text { and } \mathrm{Q}-\mathrm{O}-\mathrm{R}\end{array}$ & 0.08 & 0.01 & 4 & 0.61 & 0.08 \\
\hline
\end{tabular}

$C_{\text {max }}$, peak plasma concentration; $T_{\max }$, maximum time; AUC, area under the curve; Q-O-R, quercetin-3-O-rutinoside.
0.37 to $0.20 \mu \mathrm{M}$, increased the $T_{\max }$ from 0.25 to $1.0 \mathrm{~h}$ and delayed maximum urinary excretion from 2 to $3 \mathrm{~h}$. In contrast, a study with human subjects found that rice cake did not affect the absorption and excretion of blackcurrant anthocyanins ${ }^{(95)}$.

Ingestion of $200 \mathrm{~g}$ of strawberries with $100 \mathrm{ml}$ of double cream by human subjects did not have a significant impact on the plasma $C_{\max }$ of a pelargonidin- $O$-glucuronide compared to when only strawberries were consumed, but it did extend the $T_{\max }$ from $1 \cdot 1$ to $2 \cdot 4 \mathrm{~h}$. The overall $0-24 \mathrm{~h}$ urinary excretion of the glucuronide and other minor pelargonidin metabolites over a $24 \mathrm{~h}$ period was not affected by cream. However, anthocyanin excretion was delayed with $0-2 \mathrm{~h}$ excretion being lower and $5-8 \mathrm{~h}$ excretion being higher when the strawberries were eaten with cream. Measurement of plasma paracetamol and breath hydrogen revealed that these effects were due to cream delaying gastric emptying and extending mouth to caecum transport time ${ }^{(7)}$.

When orange juice containing $168 \mu \mathrm{mol}$ of hesperetin7-O-rutinoside, which is absorbed in the large intestine, was consumed by human subjects with and without $150 \mathrm{ml}$ of a full-fat yogurt, the yogurt did not have a significant impact on the hesperetin- $O$-glucuronide plasma pharmacokinetics. Flavanone metabolite excretion $0-5 \mathrm{~h}$ after drinking the orange juice was reduced by yogurt, but not over the full $24 \mathrm{~h}$ collection period ${ }^{(90)}$. Analysis of phenolic acids excreted in urine in the present study did, however, reveal an effect of yogurt $^{(30)}$. When only orange juice was ingested, deglycosylation of hesperetin-7- $O$-rutinoside and colonic bacteriamediated ring fission of the released aglycone resulted in $0-24 \mathrm{~h}$ urinary excretion of $62 \mu \mathrm{mol}$ of 3-hydroxyphenylhydracrylic acid and 3-methoxy-4-hydroxyphenylhydracrylic acid of undetermined chirality, 3-hydroxyphenylacetic acid, dihydroferulic acid and 3-hydroxyhippuric acid. This corresponds to $37 \%$ of hesperetin-7- $O$-rutinoside intake. When the orange juice was consumed with the yogurt, excretion of phenolic acid fell back markedly to a baseline level of $9.3 \mu \mathrm{mol}$. This effect was not due to a slowing of the mouth to caecum transit time, as measured with breath hydrogen production, so would appear to be a consequence of an as yet undetermined effect of the yogurt on the colonic microflora-mediated catabolism of hesperetin-7- $O$-rutinoside to phenolic acids.

Milk is reported to impair increases in plasma antioxidant activity occurring after the ingestion of blueberries by human subjects ${ }^{(96)}$. Other work on milk and matrix effects has centred on cocoa-based products and the impact of milk on flavan-3-ol bioavailability. In 2003, Serafini et al. ${ }^{(97)}$ reported that although consumption of $100 \mathrm{~g}$ of dark chocolate brought about an increase in human plasma antioxidant capacity, this effect was substantially reduced when the chocolate was ingested with $200 \mathrm{ml}$ of milk, and no increase in antioxidant capacity was observed after eating milk chocolate. They also showed that the absorption of (-)-epicatechin from chocolate was reduced when consumed with milk or as milk chocolate. It was hypothesised that proteins in the milk bind to the flavan-3-ols and limit their absorption from the gastrointestinal tract ${ }^{(97)}$. This report generated much controversy $^{(98)}$ with another group, which carried out experiments with a flavan-3-ol-rich cocoa drink, publishing a reply disputing any impact of milk on plasma antioxidant capacity and $(-)$-epicatechin absorption ${ }^{(99,100)}$. Two more recent studies have shown that drinking a cocoa beverage with milk does 
not affect plasma flavan-3-ol monomer levels ${ }^{(101)}$ or the quantity of flavan-3-ol metabolites excreted in urine ${ }^{(102,103)}$.

In a recent study by Mullen et al. ${ }^{(55)}$, human volunteers drank $250 \mathrm{ml}$ of a commercial cocoa made with either hot milk or hot water. Both drinks contained $45 \mu \mathrm{mol}$ of flavan-3-ol monomers. Milk did not have a significant effect on either the plasma $C_{\max }$ or $T_{\max }$ of sulphated and methylated (epi)catechin metabolites, but did bring about a reduction in (epi)catechin metabolites in $0-24 \mathrm{~h}$ urine from a level equivalent to $18.3 \%$ of intake to $10.5 \%$. This was not due to the effects of milk on either gastric emptying or on the time for the head of the meal to reach the colon ruling out the possibility that milk slowed the rate of transport of the meal through the gastrointestinal tract. The reduced excretion of the flavan-3-ol metabolites is probably a consequence of components in the milk, which either bind directly to flavan-3-ols or interfere with the mechanism involved in their transport across the wall of the small intestine into the portal vein.

The findings of the present study contrast with reports that milk does not affect the absorption of flavan-3-ols. These include a study by Roura et al. ${ }^{(102)}$, which monitored flavan3-ol metabolites in urine after drinking of cocoa containing $128 \mu \mathrm{mol}$ of flavan-3-ol monomers, a threefold higher quantity than the $45 \mu \mathrm{mol}$ ingested in the Mullen et al. study ${ }^{(55)}$. It is, however, interesting to note that although NS, urinary excretion in the study of Roura et al. was $20 \%$ lower with cocoa milk compared with cocoa water. Keogh et al. ${ }^{(101)}$ who analysed plasma $0-8 \mathrm{~h}$ after the consumption of a flavan-3-ol-rich cocoa drink also reported that milk had no effect on the absorption of catechin and epicatechin. In this instance, the ingested dose of flavan-3-ol monomers was $2374 \mu \mathrm{mol}-53$-fold higher than in the Mullen et al. study. This high dose is reflected in a $C_{\max }$ of approximately $12 \mu \mathrm{M}$ compared with the approximately $150 \mathrm{nM}$ in the Mullen et al. study. Schroeter et al. ${ }^{(99)}$ reported that milk did not influence plasma epicatechin after consumption of a cocoa beverage, which in this instance was consumed at a dose of $1314 \mu \mathrm{mol}$ of flavan-3-ol monomers for a $70 \mathrm{~kg}$ human.

There is an explanation for these seemingly contradictory reports. It would appear that with high flavan-3-ol cocoas, which are principally research products, the factors in milk that reduce absorption have minimal overall impact. With drinks with a lower flavan-3-ol content, such as the one used in the Mullen et al. study ${ }^{(55)}$, which is typical of many commercial cocoas that are on supermarket shelves ${ }^{(104)}$ and available to the general public, milk would appear to have the capacity to interfere with absorption. Interestingly, there has been a parallel debate and seemingly conflicting reports about the impact of milk on plasma flavan-3-ol and antioxidant levels after the consumption of black tea ${ }^{(104-108)}$.

\section{Evidence for the accumulation of polyphenol metabolites in body tissues}

As will be discussed later, there is evidence from a number of sources that consumption of berry extracts can delay the decline of various aspects of cognitive function in elderly rats ${ }^{(109)}$. There is, however, contradictory evidence as to whether flavonoids themselves cross the blood-brain barrier. In one of the early studies, Andres-Lacueva et al. ${ }^{(110)}$ detected trace levels of several anthocyanins in the brains of rats that had received a diet supplemented with a blueberry extract, containing unspecified amounts of anthocyanins, for a period of 10 weeks.

In a further study, $18 \mathrm{~h}$ after feeding pelargonidin to rats by gavage at a dose of $50 \mathrm{mg} / \mathrm{kg}$, the unmetabolised anthocyanidin was detected in the brains at a concentration of approximately $0 \cdot 2 \mathrm{nmol} / \mathrm{g}$ (fresh weight) ${ }^{(111)}$. In contrast, anthocyanins did not accumulate in detectable amounts in the brains of rats obtained up to $24 \mathrm{~h}$ after acute supplementation by gavage with $2.8 \mathrm{ml}$ of raspberry juice, which is a nutritional relevant dose as it is equivalent to a $70 \mathrm{~kg}$ human drinking $700 \mathrm{ml}$ of juice ${ }^{(112)}$. In contrast, following a 4-week supplementation of pigs with a blueberry extract, containing undefined amounts of anthocyanins, $300 \mathrm{pg}$ of anthocyanins/g was detected in cerebellum tissue and $700 \mathrm{pg}$ of anthocyanins/g was detected in eye tissue. Anthocyanins, however, were also found in the tissues of pigs that did not receive the blueberry supplement ${ }^{(113)}$. In another study, oral ingestion of $100 \mathrm{mg} / \mathrm{kg}$ of blackcurrant anthocyanins by rats resulted in a plasma anthocyanin $C_{\max }$ of $1.9 \mu \mathrm{g} / \mathrm{ml} 30 \mathrm{~min}$ after ingestion and a maximum concentration of anthocyanins in the whole eye of $115 \mathrm{ng} / \mathrm{g}$, also after $30 \mathrm{~min}^{(114)}$. However, in a study with male mice, feeding a bilberry extract for 2 weeks resulted in the accumulation of anthocyanins in detectable amounts in plasma, liver, kidney, testes and lungs, but not in other tissues including the brain and eyes ${ }^{(41)}$.

One of the possible reasons for the seemingly contradictory data obtained in these studies could be the use of extracts containing very high amounts of anthocyanins that could not possibly be ingested as part of a normal berry-based diet. In a recent study, where this was not the case, greenfinches consumed one blackberry per day for a period $14 \mathrm{~d}$, and approximately $18 \mathrm{~h}$ after the last feed, the birds were killed, and the brain was removed and extracted. Analysis of the extracts by HPLC with high-resolution MS revealed the presence of unmetabolised cyandin-3-O-glucoside in amounts ranging from 12 to $148 \mathrm{pmol} / \mathrm{brain}$ with an average of 40 (SD 16) $\mathrm{pmol}^{(115)}$.

As far as localisation of other flavonoids within the body is concerned, acute supplementation of rats with $\left(2-{ }^{14} \mathrm{C}\right)$ quercetin- $4^{\prime}-O$-glucoside did not result in the accumulation of any radioactivity in the brain ${ }^{(116)}$. In a human study in which volunteers drank $250 \mathrm{ml}$ of green tea containing $505 \mu \mathrm{mol}$ of flavan-3-ol monomers, typical (epi)catechin and (epi)gallocatechin metabolites were detected in plasma $2 \mathrm{~h}$ after ingestion, but they were not present in cerebrospinal fluid collected $2 \mathrm{~h}$ later ${ }^{(117)}$.

Recent elegant immunohistochemical studies have established that quercetin-3-O-glucuronide, one of the main quercetin metabolites in the circulatory system ${ }^{(33)}$, accumulates in macrophage-derived foam cells of human atherosclerotic lesions, but not in the normal aorta ${ }^{(118)}$. In vitro experiments with murine macrophage cell lines showed that quercetin-3$O$-glucuronide was taken up and deconjugated to its more bioactive aglycone quercetin, which was in turn partially converted to a methylated metabolite. In addition, mRNA expression of the class A scavenger receptor and CD36, which play key roles in the formation of foam cells, was suppressed by treatment with quercetin-3-O-glucuronide ${ }^{(118)}$. Likewise, immunohistochemical studies have also shown that (-)-epicatechin-3-O-gallate, a constituent of green tea 
that appears in plasma in trace amounts after ingestion ${ }^{(59)}$, is also specifically localised in macrophage-derived foam cells and similarly suppresses gene expression of $\mathrm{CD}^{(119)}$. These findings provide novel insights into the bioavailability of dietary flavonoids and their potential mechanism in the prevention of CVD.

\section{Biological effects of phenolics: in vitro studies with the right molecules}

Investigations of bioactivity with human or animal cell lines have made extensive use of both flavonoid aglycones and their sugar conjugates, the latter being the typical form in which they exist in planta ${ }^{(120)}$. The concentrations at which these compounds are assayed is usually in the low $\mu \mathrm{M}$ to mM range ${ }^{(121)}$. However, as outlined in the earlier section on bioavailability, following ingestion, dietary flavonoids and related polyphenols appear in the circulatory system not as the parent compounds but as glucuronide, methyl and sulphate metabolites, and that their concentrations in plasma after a normal dietary intake rarely exceed nM levels ${ }^{(23)}$. Therefore, when reviewing data on in vitro bioactivity experiments, the focus will be on studies describing the effects of metabolites that appear in the human circulatory system after the intake of dietary-relevant doses of berry-derived products.

As discussed earlier, substantial quantities of flavonoids are not absorbed in the small intestine but pass to the colon where they are degraded by the action of the microbiota. Quercetin-3-O-rutinoside, for instance, undergoes $C$-ring fission with quercetin producing a range of urinary catabolites such as 3,4-dihydroxyphenylacetic acid, 3-hydroxyphenylacetic acid and 4-hydroxy-3-methoxyphenylacetic acid (Fig. 14) ${ }^{(29)}$, some of which have lower antioxidant activity than quercetin. The same holds true for colonic degradation products of phloretin-2'-O-glucoside and 5-O-caffeoylquinic acid $^{(122)}$. In a study with faecal incubations, the rutinose moiety was cleaved from quercetin-3-O-rutinoside, and the released quercetin degraded by the pathways proposed in Fig. $16^{(123)}$. In the ferric reducing ability/power assay, the main catabolite 3,4-dihydroxyphenylacetic acid exhibited similar reducing activity to quercetin, while the other catabolites either exhibited lower reducing activity or were inactive (Table 4). The ferric reducing ability/power assay is one of the numerous methods for measuring the antioxidant activity of a molecule. To further investigate the free radical scavenging properties of the catabolites, faecal samples were analysed using the trolox equivalent antioxidant capacity test system $^{(124)}$. 3,4-Dihydroxyphenylacetic acid was similarly active in this assay, but alphitonin, taxifolin and 3,4-dihydroxybenzoic acid also showed a sizable radical scavenging activity $^{(123)}$. The difference in responses of the two assays lies in their different chemical mechanisms. The trolox equivalent antioxidant capacity assay is based on the ability of antioxidant molecules to quench the long-lived $2,2^{\prime}$ azinobis(3-ethylbenzothiazoline 6-sulfonate) radical, a bluegreen chromophore with characteristic absorption at $734 \mathrm{~nm}$, compared with that of Trolox, a water-soluble vitamin E analogue. This method is able to consider the antioxidant activity of both lipophilic and hydrophilic antioxidant molecules. The ferric reducing ability/power method is

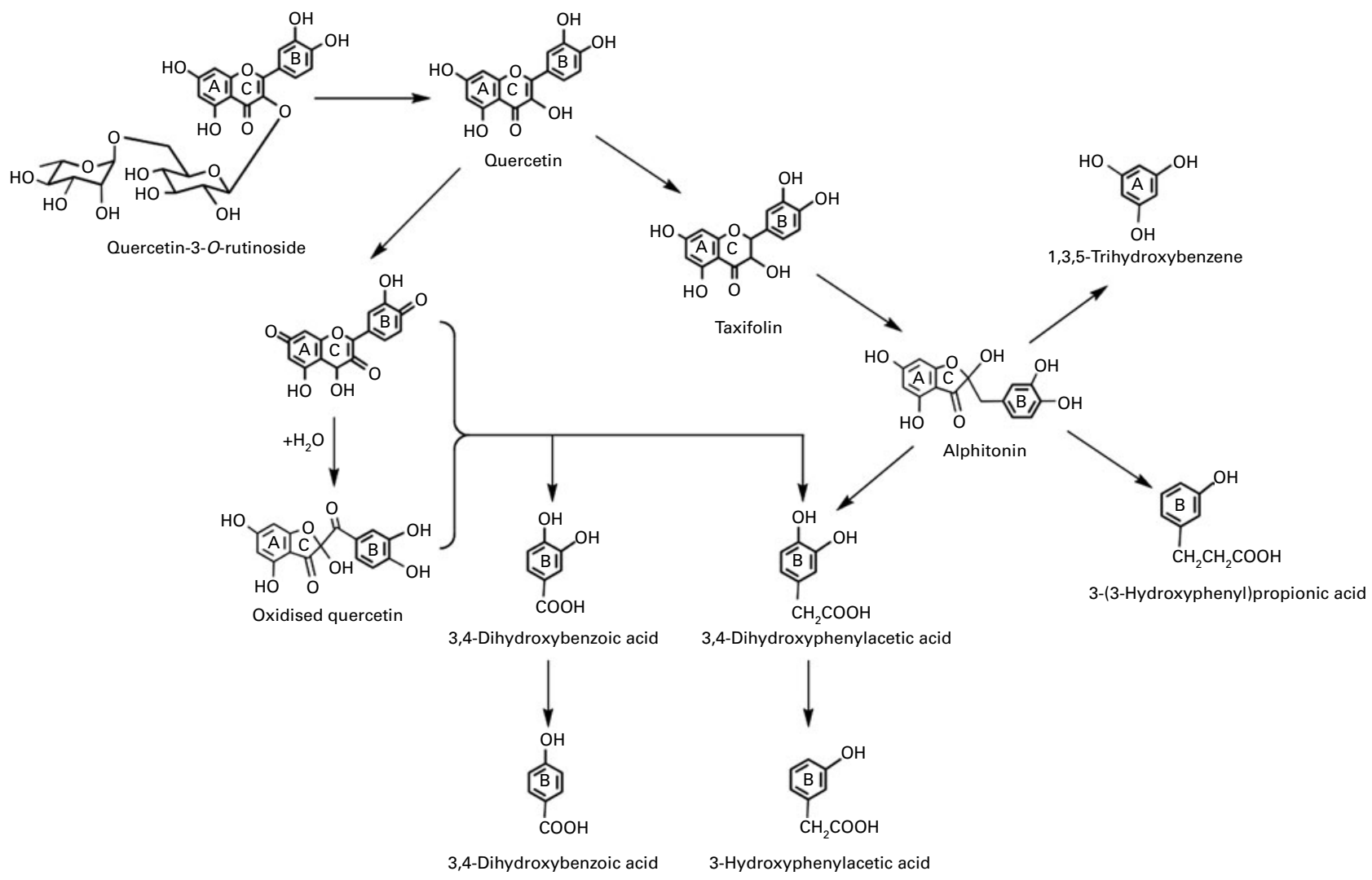

Fig. 16. Proposed routes for the catabolism of quercetin-3-O-rutinoside during in vitro incubation with human faecal slurries under anaerobic conditions ${ }^{(123)}$. 
Table 4. Ferric reducing ability/power (FRAP) antioxidant activity of $1 \mathrm{~mm}$ flavonols and phenolic acids ${ }^{(123)}$

(Mean values with their standard errors, $n 3$ )

\begin{tabular}{llc}
\hline & \multicolumn{2}{c}{ FRAP $\left(\mathrm{mM} \mathrm{Fe}^{2+}\right)$} \\
\cline { 2 - 3 } Flavonol/phenolic acid & Mean & $\mathrm{SD}$ \\
\hline Rutin & $1 \cdot 0^{\mathrm{b}}$ & $0 \cdot 1$ \\
Quercetin & $1.9^{\mathrm{a}}$ & $0 \cdot 1$ \\
Taxifolin & $0 \cdot 9^{\mathrm{b}}$ & $0 \cdot 1$ \\
3,4-Dihydroxyphenylacetic acid & $1 \cdot 8^{\mathrm{a}}$ & $0 \cdot 1$ \\
3-Hydroxyphenylacetic acid & $0 \cdot 0$ & - \\
3,4-Dihydroxybenzoic acid & $1 \cdot 0^{\mathrm{b}}$ & $0 \cdot 1$ \\
4-Hydroxybenzoic acid & 0.0 & - \\
3-(3-Hydroxyphenyl)propionic acid & $0 \cdot 0$ & - \\
1,3,5-Trihydroxybenzene & $0 \cdot 0$ & - \\
\hline
\end{tabular}

${ }^{a, b}$ Mean values with unlike superscript letters are significantly different $(P<0.01)$.

based on the reduction of the $\mathrm{Fe}^{3+}-2,4,6$-tripyridyl-S-triazine complex to the ferrous form at low $\mathrm{pH}$. This method measures the reducing ability of molecules in the sample, a feature which is directly associated to antioxidants.

The bioactivity of ellagitannins and ellagic acid and their colonic-derived catabolites, urolithins, has been assessed in a number of test systems. In a human colon cancer cell line, urolithin A and urolithin B, at concentrations achievable from a dietary intake in the lumen, influenced the expression levels of both signalling genes, such as growth factor receptors, oncogenes and tumour suppressors, and genes involved in cell cycle. This effect can be linked to cancer prevention in epithelial cells lining the colon ${ }^{(125)}$. In a similar cell model, urolithins $\mathrm{A}$ and $\mathrm{B}$ induced the expression and activity of phase I and II enzymes including cytochrome P450 monooxygenase 1A1 and UDP-glucuronosyltransferase 1A10, and inhibited several sulphotransferases ${ }^{(126)}$.

In a well-known rat model of inflammatory bowel disease, urolithins $\mathrm{A}$ and $\mathrm{B}$ reduced a number of inflammation markers (i.e. inducible nitric oxide synthase, cyclo-oxygenase-2, PGE synthase and PGE2 in colonic mucosa), favourably modulated the gut microbiota, preserved colonic architecture, but failed to decrease oxidative stress in plasma and colon mucosa ${ }^{(127)}$. Interestingly, in the same study, the formation of urolithins from punicalagin in rats fed a pomegranate extract was prevented by inflammation, suggesting that urolithin $\mathrm{A}$, in particular, could be an active anti-inflammatory compound in healthy subjects, but that other molecules, arguably punicalagin, could be responsible for anti-inflammatory activity when a pathological condition appears.

To extend these observations, several polyphenol colonic catabolites were tested in human neuronal cell cultures (human neuroblastoma SK-N-MC) exposed to low or high levels of oxidative stress induced, respectively, by 2 and $20 \mu \mathrm{M}$ concentrations of 2,3-dimethoxy-1,4-naphthoquinone ${ }^{(128)}$. In general, the tested catabolites were more protective when cells were exposed to the lower physiological level of oxidative stress. When the stronger oxidative stress was applied, mimicking pathological conditions, the catabolites provided only minimal protection of neurons. The most effective tested compounds were urolithin B, closely followed by urolithin $\mathrm{A}$ and 1,2,3-trihydroxybenzene (pyrogallol).
These results suggest that polyphenol catabolites can be protective against mild oxidative stress of neuronal cells, whereas their benefits are strongly reduced when the stress increases above physiological levels. This observation leads to the consideration of dietary polyphenols as putative preventive rather than therapeutic components. However, as discussed previously, studies have only recently begun to consider if flavonoids and their metabolites present in the bloodstream are able to reach the central nervous system by crossing the bloodbrain barrier and the experimental conditions are not always adequate ${ }^{(129)}$. Evaluating the ability of phenolic catabolites to permeate the blood-brain barrier in a proper model would be a significant step forward in the study of the effects of polyphenols on the central nervous system.

Larrosa et $a l .{ }^{(130)}$ investigated the anti-inflammatory properties of eighteen polyphenol metabolites, derived from colon microbiota. Among them, dihydrocaffeic acid, dihydroferulic acid and 3,4-dihydroxyphenylacetic acid significantly inhibited PGE2 production by CCD-18 colon fibroblast cells stimulated with IL-1 $\beta$. Inflammatory bowel diseases are very diffused pathologies in the Western world and are significantly influenced by the diet. In the aetiology and pathogenesis of Inflammatory bowel disease, an imbalance of proinflammatory cytokines seems to be involved, playing an important role in modulating inflammation. If the observations of Larrosa $\mathrm{et} \mathrm{al}$. are confirmed in clinical trials, polyphenol-rich foods or phenolic acid supplements may have potential therapeutic and/or preventive applications in Inflammatory bowel disease.

Regarding anthocyanins that occur universally in berries, the knowledge of their in vivo colonic catabolism is, as yet, limited. They appear to be poorly absorbed in the small intestine, so significant amounts probably pass into the large intestine where bacterial degradation occurs. There are reports that cyanidin-based anthocyanins undergo cleavage of the sugar moiety followed by ring fission of the released cyanidin, which produces 3,4-dihydroxybenzoic acid (protocatechuic acid) ${ }^{(131-133)}$. In one study, 3,4-dihydroxybenzoic acid effectively decreased apoptosis of cultured neural stem cells reducing the reactive oxygen species and significantly suppressing the caspase cascade ${ }^{(134)}$. 3,4-Dihydroxybenzoic acid was also able to suppresses (1-methyl-4-phenylpyridinium) ${ }^{+}$-induced mitochondrial dysfunction and apoptotic cell death in PC12 cells, showing a potential clinical application to counteract neurodegeneration such as in Parkinson's disease ${ }^{(135)}$. Finally, 3,4-dihydroxybenzoic acid was reported to be a strong apoptosis inducer in gastric adenocarcinoma cells ${ }^{(136)}$. However, the concentration of 3,4-dihydroxybenzoic acid used in cell cultures in these studies vastly exceeded the levels likely to be attained in vivo ${ }^{(132)}$, making at least the real effect of this anthocyanin catabolite questionable.

\section{Biological effects of phenolics: in vivo studies in animal models}

Evaluating the bioactivity of flavonoids and related compounds in feeding studies with animal models is a further step in attempting to unravel their putative beneficial effects. Such 'black box' experiments are designed to ascertain physiological effects exerted by the ingested compound(s) and do not provide information of the in vivo bioactive metabolites that reach target tissues or their mode of action 
in the induction of protective effects. Although there are few comparative studies, metabolism of ingested flavonoids is not necessarily the same in animal models as it is in human subjects, and frequently the dosages used in such studies are untranslatable to a regular human dietary regimen. Berries and berry-derived polyphenolic compounds have been widely investigated in animal models, and reported bioactivities include delayed cognitive decline, chemoprevention, improved cardiovascular health and reduced risk of metabolic disease.

Anthocyanin-rich extracts from bilberry, chokeberry and grape were fed for 14 weeks to male rats treated with a colon carcinogen, azoxymethane ${ }^{(137)}$. The number and multiplicity of colonic aberrant crypt foci, colonic cell proliferation, urinary levels of oxidative DNA damage and expression of cyclo-oxygenase genes were measured as biomarkers of colon cancer. The lower levels of these specific biomarkers in treated rats with respect to controls suggest a protective role of berry extracts in colon carcinogenesis and indicate multiple mechanisms of action.

Oesophageal cancer was also studied in detail in relation to berry phenolics. After 25 weeks of treatment, black raspberries, blackberries and strawberries were found to inhibit the number of oesophageal tumours (papillomas) in $\mathrm{N}$-nitrosomethylbenzylamine-treated rats by $24-56 \%$ relative to control animals ${ }^{(138)}$. A possible mechanism of action was related to berries influencing the metabolism of $N$-nitrosomethylbenzylamine leading to reduced DNA damage. In the same study, berries were found to be able to inhibit not only initiation but also tumour promotion and progression. This was probably achieved by a reduction in the premalignancy growth rate through a mechanism involving down-regulation of cyclo-oxygenase-2. In a similar study from the same group, black raspberries were able to reduce mRNA and protein expression levels of cyclo-oxygenase-2, inducible nitric oxide synthase, and c-Jun, as well as the level of PGE2 in preneoplastic lesions of the oesophagus ${ }^{(139)}$. Black raspberries were also able to suppress the development of $\mathrm{N}$-nitrosomethylbenzylamine-induced tumours in the rat oesophagus when administered as either a $5 \%$ freeze-dried powder, an anthocyanin-rich fraction or an ethanol-based organic solvent-soluble extract ${ }^{(140)}$. An organic-insoluble fraction was also effective, suggesting that non-anthocyanin components also contribute to chemoprevention.

Other type of tumours have also been studied in relation to berry supplementation in animal models. A dose-dependent decrease in haemangioendothelioma tumour size was observed in mice receiving daily oral gavage of a blueberry extract ${ }^{(141)}$. Prasain et al. ${ }^{(142)}$ reported that cranberries induced a dosedependent reduction in the number of urinary bladder cancers in female Fischer-344 rats. The efficacy of dietary berries and ellagic acid to reduce oestrogen-mediated mammary tumourigenesis has also been investigated ${ }^{(143)}$. No differences were found in tumour incidence. However, compared with the control group, ellagic acid and black raspberries significantly reduced tumour size by 75 and $69 \%$, and tumour multiplicity by 44 and $37 \%$, respectively. In contrast, consumption of blueberries resulted in a $40 \%$ reduction in tumour size but did not impact on the number of tumours.

Berries have been reported to play a major role in the prevention and attenuation of CVD. The putative mechanisms of action may be related to their ability to reduce oxidation of lipoproteins, improve serum lipid profiles and mitigate against the effects of oxidative stress and inflammation in the vascular system. Ahmet et al. ${ }^{(144)}$ recently reported that a blueberryenriched diet protected the myocardium of young male Fischer-344 rats against induced ischaemic damage and demonstrated the potential to attenuate the development of post-myocardial infarction chronic heart failure. Very similar results had previously been obtained by Toufektsian et al. ${ }^{(145)}$, who fed male Wistar rats an anthocyanin-rich diet for a period of 8 weeks. The hearts of these rats were more resistant to regional ischaemia and reperfusion insult ex vivo. With an in vivo model of coronary occlusion and reperfusion, infarct size was reduced compared to the anthocyanin-free diet. A parallel increase in myocardial glutathione levels indicates that anthocyanins or anthocyanin-derived products may modulate cardiac antioxidant defences. In male SpragueDawley rats, an anthocyanin-rich supplement significantly reduced brain infarct volume after focal cerebral ischaemic injury, and a putative mechanism was related to interaction of phenolic compounds with phospho-c-Jun $\mathrm{N}$-terminal kinase and the p53 signalling pathway ${ }^{(146)}$. In a previously cited study, 3,4-dihydroxyphenylacetic acid, dihydrocaffeic acid and dihydroferulic acid were tested for anti-inflammatory effects in a rodent model ${ }^{(130)}$. These colon-derived catabolites were able to reduce the expression of the cytokines IL-1 $\beta$, IL-8 and TNF- $\alpha$. However, once again, in most of these experiments, the dose that the animals received vastly exceeded a physiologically relevant dietary amount making it impossible to translate the observed beneficial effects to human subjects.

The effects of raspberry, strawberry and bilberry juices on early atherosclerosis in hamsters have been investigated with the animals receiving a daily dose corresponding to the consumption of $275 \mathrm{ml}$ of juice by a $70 \mathrm{~kg}$ human ${ }^{(16)}$. After 12 weeks on atherogenic diet, the berry juices inhibited aortic lipid deposition by approximately $90 \%$ (Fig. 17) and triggered reduced activity of hepatic antioxidant enzymes, which was not accompanied by lowered plasma cholesterol. The features and progression of the lesions observed in the hamster model of atherosclerosis are morphologically similar to atheromatous lesions observed in human subjects ${ }^{(147)}$ This feature, when considered along with the fact that the daily dose of juice received by the hamsters was nutritionally relevant, enables the findings to be related to a human context. Atherosclerosis, in general, and the intima-media thickness of the common carotid artery have been shown to constitute a good predictor of future incidence of ischaemic stroke ${ }^{(148)}$, and this highlights the potential importance of polyphenolrich berry juice intake for a reduced incidence of cardiovascular and cerebrovascular disease.

Berries and their phenolic components have been shown to compensate physiological variables in metabolic diseases such as type 2 diabetes and its most common precursors, obesity and insulin resistance. DeFuria et al. ${ }^{(149)}$ tested the hypothesis that supplementation of rats on a high-fat diet with a blueberry powder could protect against adipose tissue-related inflammation and subsequent insulin resistance. The adipose tissue of rats on the high-fat diet exhibited a proinflammatory pattern of gene expression as reflected in up-regulation of TNF- $\alpha$, IL-6, monocyte chemoattractant protein 1 and inducible nitric oxide synthase. This shift towards inflammation was 

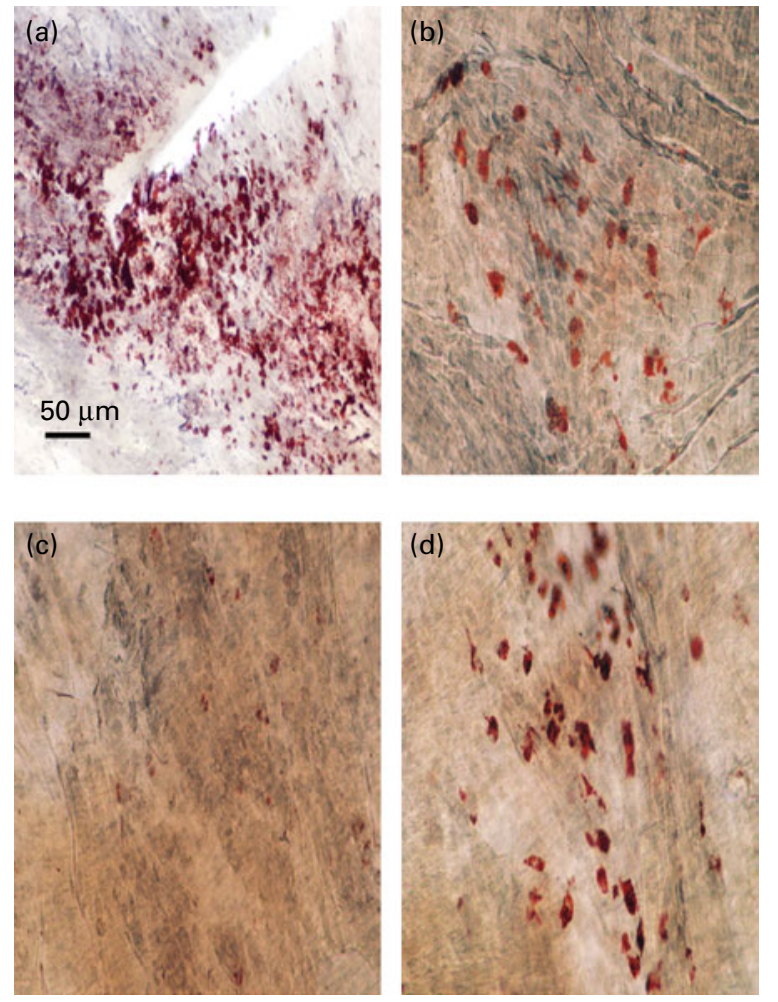

Fig. 17. Photomicrographs of hamster aortic arches after 12 weeks on an atherogenic diet (control (a)) and 12 weeks on an atherogenic diet supplemented with either bilberry juice (b), raspberry juice (c) or strawberry juice (d). The micrographs are examples of the aortic arch surface covered by lipid inclusion in the intima with lipids coloured red using Oil Red $O$ stain $^{(16)}$. (A colour version of this figure can be found online at journals.cambridge. org/bjn).

reduced or completely absent in blueberry-fed rats, which also showed reduced hyperglycaemia and insulin resistance compared to unsupplemented control animals. Although further research is required, these observations demonstrate that berries and their phenolic components might provide metabolic benefits to counteract obesity-associated pathology in human subjects.

Single anthocyanins have been tested for their potential antidiabetic activity. In a study with male Wistar rats, intraperitoneal injection of pelargonidin normalised elevated glycaemia and improved serum insulin levels in diabetic rats. The typical biochemical symptoms of induced diabetes, such as lower serum levels of superoxide dismutase and catalase, increased concentrations of malondialdehyde and fructosamine, were effectively reverted to normal values after pelargonidin administration $^{(150)}$. One possible mechanism is linked to the anthocyanin counteracting $\mathrm{Hb}$ glycation, consequent $\mathrm{Fe}$ release from the prosthetic group and $\mathrm{Fe}$-mediated oxidative damage. A 5-week intake of cyanidin-3-O-glucoside by type 2 diabetic mice has been shown to significantly reduce blood glucose concentration and enhance insulin sensitivity ${ }^{(151)}$. Apparently, one of the mechanisms involved is linked to up-regulation of GLUT4, which is present in muscle and adipose tissue cells, and down-regulation of retinol binding protein 4 at the adipose tissue level, with a consequent down-regulation of inflammatory-related adipocytokines. In a recent review, Tsuda ${ }^{(152)}$ stated that anthocyanins can exert antiobesity actions through improvement of adipocyte function, and that they may also be important dietary components for preventing metabolic syndrome.

There is a wealth of the literature from Joseph and colleagues, at the USDA-ARS Human Nutrition Research Center at the Tufts University in Boston, on the protective effects of berry anthocyanins against brain ageing and the consequent decline in cognitive performance in animal models. After feeding elderly F344 rats a $2 \%$ blueberry extract for 10 weeks, trace levels of parent anthocyanins were found in the cerebellum, cortex, hippocampus or striatum ${ }^{(110)}$. The elderly rats also performed better in a test of spatial learning and memory, and the performance was directly and significantly correlated to brain anthocyanin concentration, suggesting, for the first time, that these compounds may deliver their function directly to the central nervous system. In the Morris water maze test, rats that drank a $10 \%$ Concord purple grape juice for 3 months exhibited improvements in cognitive performance, principally spatial learning and memory, while those given a $50 \%$ grape juice supplement had improvements in motor function ${ }^{(153)}$. A blackberry diet also lead to similar results, improving motor performance based on balance and co-ordination. After blackberry consumption, rats had significantly greater working or short-term memory performance than the unfed controls ${ }^{(154)}$. One of the mechanisms involved in these effects could be related to inflammation, as consumption of blueberry polyphenols was able to attenuate learning impairments following neurotoxic insult with parallel antiinflammatory actions, probably by acting on gene expression $^{(155,156)}$. Anthocyanins are also able to improve learning and memory of ovariectomised rats ${ }^{(157)}$. Ovariectomy caused oestrogen deficit in the animals, which in turn is associated with mental health disorders, emotional difficulties, memory impairment and other cognitive failures; the supplementation with red grape anthocyanins resulted in memory-enhancing effects. Therefore, another possible mechanism involved in cognitive-related effects of anthocyanins could be their phyto-oestrogenic effects, with clear implications for human subjects. Another mechanism could be related to systemic or central antioxidant protection, as observed by Shih et al. ${ }^{(158)}$ who fed senescence-accelerated mice with a basal diet supplemented with a 0.18 and $0.9 \%$ mulberry extract for 12 weeks. Treated animals showed a higher antioxidant enzyme activity and reduced lipid oxidation in both the brain and liver.

Finally, it is interesting to note that berry-derived polyphenols may be active in different and specific brain regions. Morris water maze tests showed that strawberry supplementation to high-energy and charge particles irradiated - rats partially overcame spatial deficits as animals were better able to retain place information - behaviour associated with the a hippocampus. A blueberry supplementation, however, seemed to improve reversal learning, a behaviour more dependent on intact striatal function ${ }^{(159)}$.

Once again, it must be kept in mind that no easy translation can be made from animal models to human subjects. This is basically due to intrinsic differences between animal and human behaviour and basic physiology and due to the strictly controlled conditions that can be applied to animals, but not to human subjects, in intervention studies. However, it must be pointed out that these observations in very selected animal models are suggestive of a strong and specific bioactivity of 
polyphenolic compounds, which are explained by plausible mechanisms and accompanied by observable changing at the biochemical level. Interest in possible biological effects of berry consumption in human subjects is, therefore, based on solid foundations and of compelling interest.

\section{Biological effects of berry phenolics: studies in human subjects}

Several cross-sectional studies reported a putative protective role of phenolic compounds towards a long list of different and multifactorial diseases in human subjects ${ }^{(160-165)}$. Nevertheless, these studies did not specifically investigate all the individual polyphenol subclasses, and the available data provide no evidence of protective effects exerted by anthocyanins, which are among the main flavonoids in berries. However, in one study, higher intake of anthocyanins was associated with reduced risk of non-Hodgkin lymphoma in a population recruited in Surveillance, Epidemiology and End Results registries in four US states ${ }^{(166)}$.

Usually, randomised intervention studies are designed and performed to corroborate epidemiological evidence, and this is one of the reasons why reports describing such interventions in the medical literature are sparse and inconclusive. The first target of intervention studies designed to supplement antioxidant molecules in human subjects is always the most elusive physiopathological variable: oxidative stress. Møller et al. ${ }^{(167)}$ recruited fifty-seven volunteers for 3-week controlled and randomised parallel feeding study with either blackcurrant juice, an anthocyanin-rich drink or a placebo control beverage. It was found that even large amounts of dietary antioxidants did not reduce the levels of oxidative DNA damage, which are measured as strand breaks and as endonuclease III and formamidopyrimidine DNA glycosylase-sensitive sites by the comet assay. DNA was, however, significantly protected against oxidative insult in twenty-one haemodialysis patients in a pilot intervention study by $200 \mathrm{ml} / \mathrm{d}$ intake for a 4 -week period of an anthocyanin-rich red fruit juice ${ }^{(168)}$. Reduced DNA oxidation damage was accompanied by decreased protein and lipid peroxidation and an increase in glutathione.

Three further studies report positive effects in older human subjects. Thirty-six grams of a lyophilised red grape powder was able to significantly reduce systemic oxidative stress as measured by urinary F2-isoprostanes in twenty postmenopausal women ${ }^{(169)}$. The supplement was also able to positively alter lipoprotein metabolism and inflammatory markers $(\mathrm{TNF}-\alpha)$, therefore supposedly reducing recognised cardiovascular risk factors. Consumption of tart cherry juice for 2 weeks, containing high levels of anthocyanins, was able to reduce the ischaemia/reperfusion-induced F2-isoprostane response in plasma and urinary excretion of oxidised nucleic acids, a measure of DNA oxidative damage, in twelve volunteers aged 69 (SD 4) years ${ }^{(170)}$. Finally, in twenty-six patients receiving haemodialysis and fifteen healthy subjects, daily consumption of $100 \mathrm{ml}$ of red grape juice for a period of $14 \mathrm{~d}$ increased the antioxidant capacity of plasma, without affecting concentrations of uric acid or vitamin $\mathrm{C}$, reduced oxidised LDL and increased the level of cholesterol-standardised $\alpha$-tocopherol ${ }^{(171)}$.

Anthocyanins from different sources have been associated with vascular health-related improvements in vivo. Acute consumption of capsules of blackcurrant anthocyanins by healthy volunteers was able to increase forearm blood flow with no significant difference in muscle oxygen consumption $^{(172)}$. In the same study, healthy subjects took the capsules daily for 2 weeks, and the treatment significantly reduced oxy$\mathrm{Hb}$ decline and alleviated muscle stiffness after a workload. Most importantly, daily consumption of a pomegranate juice for 3 months positively affected myocardial perfusion in forty-five patients with CHD and myocardial ischaemia in a randomised, placebo-controlled, double-blind study ${ }^{(173)}$.

Inflammatory biomarkers are another common target of human interventional studies, being relatively easy to measure in vivo and strictly related with cardiovascular, metabolic and cancer risk. In a previously cited study, red grape juice supplementation of haemodialysis patients for 3 weeks significantly reduced plasma monocyte chemoattractant protein 1 , an inflammatory biomarker associated with CVD risk $^{(171)}$. The same biomarker was reduced in another acute study in which healthy volunteers received $13 \mathrm{~g}$ of a red wine anthocyanin extract ${ }^{(174)}$. C-reactive protein, another biomarker of systemic inflammation, was also significantly reduced along with fructosamine, glutathione and total cholesterol in thirtytwo type 2 diabetes mellitus patients receiving a grape seed extract, presumably rich in procyanidins, for 4 weeks in a double-blinded randomised crossover trial ${ }^{(175)}$.

Finally, a recent Cochrane review reports some evidence that cranberry juice may decrease the number of symptomatic urinary tract infections over a 12-month period, particularly for women with recurrent episodes ${ }^{(176)}$.

\section{Conclusion and future perspectives}

In conclusion, there is a strong evidence that polyphenols from berry fruits are absorbed to varying degrees and deliver positive effects at various levels in the human body. However, more research is needed to fully understand which molecules are effective and what mechanisms are involved in their action. Some focused investigation to reach this target could be summarised as follows: (1) performing feeding studies of ${ }^{14} \mathrm{C}$-labelled anthocyanins to rats to unravel their main catabolites and clarify their fate within the body; (2) organising and carrying out up-to-date bioavailability of human studies of blackcurrant phenolics with healthy subjects, applying different models (ileostomy volunteers, kidney- and liver-impaired volunteers) to understand the main sites of absorption and catabolism of these components; (3) setting up synthesis and in vitro studies to fully characterise the bioactivity of polyphenol catabolites generated in vivo. This should be done with different in vitro models (inflammation, endothelial function, insulin sensitivity, glycation and ageing); (4) performing medium to long-term feeding studies with berries to evaluate modification of various biomarkers of disease (inflammation, blood pressure, blood lipids and endothelial function); (5) setting up detailed studies to understand the interaction between berry phenolics and colon microflora. This approach should be bidirectional, with studies demonstrating how berry consumption could modify the colon environment and how a specific microbiota could modify the reaction towards berry phenolic absorption, catabolism and bioactivity; (6) identifying berry phenolic catabolites able to cross the blood-brain barrier by means of high-resolution analytical techniques. 


\section{Acknowledgements}

None of the authors have conflicts of interest (financial, professional or personal) that are relevant to the manuscript. The author's responsibilities were as follows: D. D. R., G. B. and A. C. conducted the initial literature review and wrote the manuscript and abstract. A. C. designed and prepared figures and tables.

\section{References}

1. Boyles MJ \& Wrolstad RE (1993) Anthocyanin composition of red raspberry juice: Influences of cultivar processing and environmental factors. J Food Sci 58, 1135-1141.

2. Hakkinen SH, Karenlampi SO, Mykkanen HM, et al. (2000) Influence of domestic processing and storage on flavonol contents in berries. J Agric Food Chem 48, 2960-2965.

3. Hakkinen SH \& Torronen AR (2000) Content of flavonols and selected phenolic acids in strawberries and Vaccinium species: influence of cultivar, cultivation site and technique. Food Res Int 33, 517-524.

4. Mäattä KR, Kamal-Eldin A \& Torronen AR (2003) High performance liquid chromatography (HPLC) analysis of phenolic compounds in berries with diode array and electrospray ionisation mass spectrometric (MS) detection: Ribes species. J Agric Food Chem 51, 6736-6744.

5. Wu X, Gu L, Prior RL, et al. (2004) Characterisation of anthocyanins and proanthocyanidins in some cultivars of Ribes, Aronia, and Sambucus and their antioxidant capacity. J Agric Food Chem 52, 7846-7856.

6. Borges G, Degénéve A, Mullen W, et al. (2010) Identification of flavonoid and phenolic antioxidants in blackcurrants, blueberries, raspberries, redcurrants and cranberries. J Agric Food Chem (In the Press).

7. Mullen W, Edwards CA, Serafini M, et al. (2008) Bioavailability of pelargonidin-3-O-glucoside and its metabolites in humans following the ingestion of strawberries with and without cream. J Agric Food Chem 56, 713-719.

8. Dégenéve A (2004) Antioxidants in fruits and vegetables. MSc Thesis, University of Glasgow.

9. Cho MJ, Howard LR, Prior RL, et al. (2004) Flavonoid glycosides and antioxidant capacity of various blackberry, blueberry and red grape genotypes determined by high-performance liquid chromatography/mass spectrometry. J Sci Food Agric 84, 1771-1782.

10. Hager TJ, Howard LR \& Liyanage R (2008) Ellagitannin composition of blackberry as determined by HPLC-ESI-MS and MALDI-TOF-MS. J Agric Food Chem 56, 661-669.

11. Mullen W, McGinn J, Lean MEJ, et al. (2002) Ellagitannins, flavonoids, and other phenolics in red raspberries and their contribution to antioxidant capacity and vasorelaxation properties. J Agric Food Chem 50, 6902-6909.

12. Mullen W, Stewart AJ, Lean MEJ, et al. (2002) Effect of freezing and storage on the phenolics, ellagitannins, flavonoids and antioxidant capacity of red raspberries. J Agric Food Chem 50, 5197-5201.

13. Mullen W, Yokota T, Lean MEJ, et al. (2003) Analysis of ellagitannins and conjugates of ellagic acid and quercetin in raspberry fruit by LC-MS. Phytochemistry 64, 617-624.

14. Prior RL, Lazarus SA, Cao G, et al. (2001) Identification of procyanidins and anthocyanins in blueberries and cranberries (Vaccinium spp.) using high-performance liquid chromatography/mass spectrometry. J Agric Food Chem 49 , $1270-1276$.

15. McGhie TK, Aingie GD, Barnet LE, et al. (2003) Anthocyanin glycosides from berry fruit are absorbed and excreted unmetabolised by both human and rats. J Agric Food Chem 51, 4539-4548.
16. Rouanet J-M, Décorde K, Del Rio D, et al. (2010) Berry juices, teas, antioxidants and the prevention of atherosclerosis in hamsters. Food Chem 118, 266-271.

17. Hertog MGL, Hollman PCH \& Katan MB (1992) Content of potentially anticarcinogenic flavonoids of 28 vegetables and 9 fruits commonly consumed in The Netherlands. J Agric Food Chem 40, 2379-2383.

18. Hertog MGL, Hollman PCH \& Venema DP (1992) Optimization of quantitative HPLC determination of potentially anticarcinogenic flavonoids in fruit and vegetables. J Agric Food Chem 40, 1591-1598.

19. Hakkinen SH, Karenlampi SO, Heinonen M, et al. (1999) Content of the flavonols quercetin, myricetin and kaempferol in 25 edible berries. J Agric Food Chem 47, 2274-2279.

20. Gu L, Kelm MA, Hammerstone JF, et al. (2004) Concentrations of proanthocyanidins in common foods and estimations of normal consumption. J Nutr 134, 613-617.

21. Amakura Y, Okada M, Tsuji S, et al. (2000) High performance liquid chromatographic determination with photo diode array detection of ellagic acid in fresh and processed fruits. J Chromatogr A 896, 87-93.

22. Hakkinen SH, Karenlampi SO, Mykkanen HM, et al. (2000) Ellagic acid content in berries: influence of domestic processing and storage. Eur Food Res Technol 212, 75-80.

23. Crozier A, Jaganath IB \& Clifford MN (2009) Dietary phenolics: chemistry, bioavailability and effects on health. Nat Prod Rep 26, 1001-1043.

24. Schuster B \& Herrmann K (1985) Hydroxybenzoic acid and hydroxycinnamic acid derivatives in soft fruits. Phytochemistry 24, 2761-2764.

25. Donovan JL, Manach C \& Faulks RM (2006) Absorption and metabolism of dietary secondary metabolites. In Plant Secondary Metabolites. Occurrence, Structure and Role in the Human Diet, pp. 303-351 [A Crozier, MN Clifford and H Ashihara, editors]. Oxford: Blackwell Publishing.

26. Day AJ, Canada FJ, Diaz JC, et al. (2000) Dietary flavonoid and isoflavone glycosides are hydrolysed by the lactase site of lactase phlorizin hydrolase. FEBS Lett 468, 166-170.

27. Gee JM, DuPont SM, Day AJ, et al. (2000) Intestinal transport of quercetin glycosides in rats involves both deglycosylation and interaction with the hexose transport pathway. J Nutr 130, 2765-2771.

28. Kottra G \& Daniel H (2007) Flavonoid glycosides are not transported by the human $\mathrm{Na}^{+} /$glucose transporter when expressed in Xenopus laevis oocytes, but effectively inhibit electrogenic glucose uptake. J Pharmacol Exp Ther 322, 829-835.

29. Jaganath IB, Mullen W, Edwards CA, et al. (2006) The relative contribution of the small and large intestine to the absorption and metabolism of rutin in man. Free Radic Res 40, $1035-1046$.

30. Roowi S, Mullen W, Edwards CA, et al. (2009) Yoghurt impacts on the excretion of phenolic acids derived from colonic breakdown of orange juice flavanones in humans. Mol Nutr Food Res 53, S44-S53.

31. Williamson G \& Clifford MN (2010) Colon metabolites of berry polyphenolics: the missing link to biological activity. GlaxSmithKline Report.

32. Manach C, Williamson G, Morand C, et al. (2005) Bioavailability and bioefficacy of polyphenols in humans. I. Review of 97 bioavailability studies. Am J Clin Nutr 81, 230S-242S.

33. Mullen W, Edwards CA \& Crozier A (2006) Absorption, excretion and metabolic profiling of methyl-, glucuronyl-, glucosyl and sulpho-conjugates of quercetin in human plasma and urine after ingestion of onions. Br J Nutr 96, 107-116.

34. Reeve DR \& Crozier A (1980) Quantitative analysis of plant hormones. In Hormonal Regulation of Development 1. Molecular Aspects of Plant Hormones, vol. 9, pp. 203-280 
[J MacMillan, editor]. Encyclopaedia of plant physiology new series. Heidelberg: Springer-Verlag.

35. Gu L, Laly M, Chang HC, et al. (2005) Isoflavone conjugates are underestimated in tissues using enzymatic hydrolysis. J Agric Food Chem 53, 6858-6863.

36. Miyazawa T, Nakagawa K, Kudo M, et al. (1999) Direct intestinal absorption of red fruit anthocyanins, cyanidin-3-glucoside and cyanidin-3,5-diglucoside, into rats and humans. J Agric Food Chem 47, 1083-1091.

37. Milbury P, Cao G, Prior RL, et al. (2002) Bioavailablility of elderberry anthocyanins. Mech Ageing Develop 2002, 997-1006.

38. Cooney JM, Jensen JD \& McGhie TK (2004) LC-MS identification of anthocyanins in boysenberry extract and anthocyanin metabolites in human urine following dosing. J Sci Food Agric 84, 237-245.

39. Ichiyanagi T, Shida Y, Rahman MM, et al. (2005) Extended glucuronidation is another major path of cyanidin $3-O-\beta-\mathrm{D}-$ glucopyranoside metabolism in rats. J Agric Food Chem 53, 7312-7319.

40. Borges G, Roowi S, Rouanet J-M, et al. (2007) The bioavailability of raspberry anthocyanins and ellagitannins. Mol Nutr Food Res 51, 714-725.

41. Sakakibara H, Ogawa T, Koyanagi A, et al. (2009) Distribution and excretion of bilberry anthocyanins in mice. $J$ Agric Food Chem 57, 7681-7686.

42. Wu X, Pittman HE, McKay S, et al. (2005) Aglycones and sugar moieties alter anthocyanin absorption and metabolism after berry consumption in weanling pigs. J Nutr 135, 2417-2424.

43. Prior RL \& Wu X (2006) Anthocyanins: structural characteristics that result in unique metabolic patterns and biological activities. Free Radic Res 40, 1014-1028.

44. Wu X, Beecher G, Holden JM, et al. (2006) Concentrations of anthocyanins in common foods in the United States and estimation of normal consumption. J Agric Food Chem 54, 4069-4075.

45. Felgines C, Talavéra S, Gonthier M-P, et al. (2003) Strawberry anthocyanins are recovered in urine as glucuro- and sulfoconjugates in humans. J Nutr 133, 1269-1301.

46. Carkeet C, Clevidence BA \& Novotny JA (2008) Anthocyanin excretion by humans increases linearly with increasing strawberry dose. J Nutr 2008, 897-902.

47. Felgines C, Talavéra O, Texier A, et al. (2005) Blackberry anthocyanins are mainly recovered from urine as methylated and glucuronidated conjugates in humans. J Agric Food Chem 53, $7721-7727$.

48. Kay CD \& Holub BJ (2002) The effect of wild blueberry consumption on postprandial serum antioxidant status in human subjects. Br J Nutr 88, 389-397.

49. Mazza G, Kay CD, Cottrell T, et al. (2002) Absorption of anthocyanins from blueberries and serum antioxidant status in human subjects. J Agric Food Chem 50, 7731-7737.

50. Wu X, Cao G \& Prior RL (2002) Absorption and metabolism of anthocyanins in elderly women after consumption of elderberry or blueberry. J Nutr 132, 1865-1871.

51. Clifford MN (2000) Anthocyanins - nature, occurrence and dietary burden. J Sci Food Agric 80, 1063-1072.

52. Woodward G, Kroon P, Cassidy A, et al. (2009) Anthocyanin stability and recovery: implications for the analysis of clinical and experimental samples. J Agric Food Chem 57, 5271-5278.

53. Määttä-Riihinen KR, Kähkkönen MP, Törrönen RA, et al. (2005) Catechins and procyanidins in berries of vaccinium species and their antioxidant activity. J Agric Food Chem 53, 8485-8491.

54. Crozier A, Yokota T, Jaganath IB, et al. (2006) Secondary metabolites as dietary components in plant-based foods and beverages. In Plant Secondary Metabolites. Occurrence, Structure and Role in the Human Diet, pp. 208-302 [A Crozier, MN Clifford and $\mathrm{H}$ Ashihara, editors]. Oxford: Blackwell Publishing.
55. Mullen W, Borges G, Donovan JL, et al. (2009) Milk decreases urinary excretion but not plasma pharmacokinetics of cocoa flavan-3-ol metabolites in humans. Am J Clin Nutr 89, 1784-1791.

56. Donovan JL, Crespy V, Oliveira M, et al. (2006) (+)-Catechin is more bioavailable than $(-)$-catechin: relevance to the bioavailability of catechin from cocoa. Free Radic Res 40, 1029-1034.

57. Stalmach A, Troufflard S, Serafini M, et al. (2009) Absorption, metabolism and excretion of Choladi green tea flavan-3-ols by humans. Mol Nutr Food Res 53, S44-S53.

58. Baba S, Osakabe N, Yasuda A, et al. (2000) Bioavailability of (-)-epicatechin upon intake of chocolate and cocoa in human volunteers. Free Radic Res 33, 635-641.

59. Stalmach A, Mullen W, Steiling H, et al. (2010) Absorption, metabolism, efflux and excretion of green tea flavan-3-ols in humans with an ileostomy. Mol Nutr Food Res (In the Press).

60. Kida T, Suzuki N, Matsumoto F, et al. (2000) Identification of biliary metabolites of $(-)$-epigallocatechin gallate in rats. J Agric Food Chem 48, 4151-4155.

61. Kohri T, Nanjo F, Suzuki M, et al. (2001) Synthesis of (-)$\left[4-{ }^{3} \mathrm{H}\right]$ epigallocatechin gallate and its metabolic fate in rats after intravenous administration. J Agric Food Chem 49, 1042-1048.

62. Zhu QY, Zhang AQ, Tsang D, et al. (1997) Stability of green tea catechins. J Agric Food Chem 45, 4624-4628.

63. Yoshino K, Suzuki M, Sasaki K, et al. (1999) Formation of antioxidants from (-)-epigallocatechin gallate in mild alkaline fluids, such as authentic intestinal juice and mouse plasma. J Nutr Biochem 10, 223-229.

64. Record R \& Lane JM (2001) Simulated intestinal digestion of green and black teas. Food Chem 73, 481-486.

65. Green RJ, Murphy AS, Schulz B, et al. (2007) Common tea formulations modulate in vitro digestive recovery of green tea catechins. Mol Nutr Food Res 51, 1152-1162.

66. Auger C, Hara Y \& Crozier A (2008) Bioavailability of polyphenon E flavan-3-ols in humans with an ileostomy. J Nutr 138, 1535S-1542S.

67. Packer L, Rimbach G \& Virgili F (1999) Antioxidant activity and biologic properties of a procyanidin-rich extract from pine (Pinus maritima) bark, pycnogenol. Free Radic Biol Med 27, 704-724.

68. Simonetti P, Ciappellano S, Gardana C, et al. (2002) Procyanidins from Vitis vinifera seeds: in vivo effects on oxidative stress. J Agric Food Chem 50, 6217-6221.

69. Yamakoshi J, Kataoka S, Koga T, et al. (1999) Proanthocyanidin-rich extract from grape seeds attenuates the development of aortic atherosclerosis in cholesterol-fed rabbits. Atherosclerosis 142, 139-149.

70. Bomser JA, Sinletary KW, Wallig MA, et al. (1999) Inhibition of TPA-induced tumor promotion in CD-1 mouse epidermis by a polyphenolic fraction from grape seeds. Cancer Lett 135, $151-157$.

71. Williamson G \& Manach C (2005) Bioavailability and bioefficacy of polyphenols in humans. II. Review of 93 intervention studies. Am J Clin Nutr 81, 243S-255S.

72. Espín JC, García-Conesa MT \& Tomás-Barberán FA (2007) Nutraceuticals: facts and fiction. Phytochemistry 68, 2986-3008.

73. Déprez S, Brezillon C, Rabot S, et al. (2000) Polymeric proanthocyanidins are catabolized by human colonic microflora into low-molecular-weight phenolic acids. J Nutr 130, 2733-2738.

74. Gonthier M-P, Donovan JL, Texier O, et al. (2003) Metabolism of dietary procyanidins in rats. Free Radic Biol Med 35, 837-844. 
75. Appeldoorn MM, Vincken VP, Aura AM, et al. (2009) Procyanidin dimers are metabolized by human microbiota with 2-(3,4-dihydroxyphenyl)acetic acid and 5-(3,4-dihydroxyphenyl)- $\gamma$-valerolactone as the major metabolites. J Agric Food Chem 57, 1084-1092.

76. Ward NC, Croft KD, Pudley IB, et al. (2004) Supplementation with grape seed polyphenols results in increased urinary excretion of 3-hydroxyphenylpropionic acid, an important metabolite of proanthocyanidins in humans. J Agric Food Chem 52, 5545-5549.

77. Spencer JPE, Chaudry F, Pannala AS, et al. (2000) Decomposition of cocoa procyanidins in the gastric milieu. Biochem Biophys Res Commun 272, 236-241.

78. Donovan JL, Manach C, Rios L, et al. (2002) Procyanidins are not bioavailable in rats fed a single meal containing a grapeseed extract or the procyanidin dimer B3. Br J Nutr 87, 299-306.

79. Rios L, Bennett RN, Lazarus SA, et al. (2002) Cocoa procyanidins are stable during gastric transit in humans. Am J Clin Nutr 76, 1106-1110.

80. Tsang C, Auger C, Bornet A, et al. (2005) The absorption, metabolism and excretion of flavan-3-ols and procyanidins following the ingestion of a grape seed extract by rats. Br J Nutr 94, 170-181.

81. Sano A, Yamakoshi J, Tokutake S, et al. (2003) Procyanidin B1 is detected in human serum after intake of proanthocyanidin-rich grape seed extract. Biosci Biotechnol Biochem 77, $1140-1143$.

82. Holt RR, Lazarus SA, Sullards MC, et al. (2002) Procyanidin

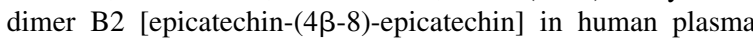
after the consumption of a flavanol-rich cocoa. Am J Clin Nutr 76, 798-804.

83. Corder R (2008) Red wine, chocolate and vascular health: developing the evidence base. Heart 94, 821-823.

84. Shoji T, Masumoto S, Moriichi N, et al. (2006) Apple procyanidin oligomers absorption in rats after oral administration: analysis of procyanidins in plasma using the Porter method and high-performance liquid chromatography/ tandem mass spectrometry. J Agric Food Chem 54, 884-892.

85. Cerdá B, Espín JC, Parra S, et al. (2004) The potent in vitro antioxidant ellagitannins from pomegranate juice are metabolised into bioavailable but poor antioxidant hydroxy- $6 \mathrm{H}-$ dibenzopyran-6-one derivatives by the colonic microflora of healthy humans. Eur J Nutr 43, 205-220.

86. Seeram NP, Henning SM, Zhang Y, et al. (2006) Pomegranate juice ellagitannin metabolites are present in human plasma and some persist in urine for up to 48 hours. J Nutr 136, 2481-2485.

87. Mertens-Talcott SU, Jilma-Stohlawetz P, Rios J, et al. (2006) Absorption, metabolism, and antioxidant effects of pomegranate (Punica granatum L.) polyphenols after ingestion of a standardized extract in healthy human volunteers. J Agric Food Chem 54, 8956-8961.

88. Cerdá B, Tomás-Barberán FA \& Espín JC (2005) Metabolism of antioxidant and chemopreventive ellagitannins from strawberries, raspberries, walnuts, and oak-aged wine in humans: identification of biomarkers and individual variability. $J$ Agric Food Chem 53, 227-235.

89. Espin JC, González-Barrio R, Cerdá B, et al. (2007) Iberian pig as a model to clarify obscure points in the bioavailability and metabolism of ellagitannins in humans. J Agric Food Chem 55, 10476-10485.

90. Mullen W, Archeveque M-A, Edwards CA, et al. (2008) Bioavailability and metabolism of orange juice flavanones in humans: impact of a full fat yogurt. J Agric Food Chem 56, $11157-11164$.
91. Dendougui F \& Schwedt G (2004) In vitro analysis of binding capacities of calcium to phytic acid in different food samples. Eur Food Res Tech 219, 409-415.

92. Matsumoto H, Ito K, Yonekura K, et al. (2007) Enhanced absorption of anthocyanins after oral administration of phytic acid in rats and humans. J Agric Food Chem 55, 2489-2496.

93. Walton MC, Lentle RG, Reynolds GW, et al. (2006) Anthocyanin absorption and antioxidant status of pigs. J Agric Food Chem 54, 7940-7946.

94. Walton MC, Hendriks WH, Broomfield AM, et al. (2009) Viscous food matrix influences absorption and excretion but not metabolism of blackcurrant anthocyanins in rats. $J$ Food Sci 74, H22-H229.

95. Neilsen ILF, Dargste LO, Rav-Haren G, et al. (2003) Absorption and excretion of blackcurrant anthocyanins in humans and Watanabe heritable hyperlipidemic rabbits. J Agric Food Chem 51, 2813-2820.

96. Serafini M, Testa MF, Villaño D, et al. (2009) Antioxidant activity of blueberry fruit is impaired by association with milk. Free Radic Biol Med 46, 769-774.

97. Serafini M, Bugianesi R, Maiaini G, et al. (2003) Plasma antioxidants from chocolate. Nature 424, 1013.

98. Halliwell B (2003) Health benefits of eating chocolate? Nature 426, 787.

99. Schroeter H, Holt RR, Orozco TJ, et al. (2003) Milk and the absorption of flavanols. Nature 426, 787-788.

100. Serafini M \& Crozier A (2003) Milk and the absorption of flavanols - reply. Nature 426, 788.

101. Keogh JB, McInerney J \& Clifton PM (2007) The effect of milk protein on the bioavailability of cocoa polyphenols. J Food Sci 72, S230-S233.

102. Roura E, Andrès-Lacueva C, Estruch R, et al. (2007) Milk does not affect the bioavailability of cocoa powder flavonoid in healthy human. Ann Nutr Metab 51, 493-498.

103. Roura E, Andrès-Lacueva C, Estruch R, et al. (2008) The effect of milk as a food matrix for polyphenols on the excretion profile of cocoa (-)-epicatechin metabolites in healthy human subjects. Br J Nutr 100, 846-851.

104. Miller KB, Hurst WJ, Payne MJ, et al. (2008) Impact of alkalization on the antioxidant and flavanol content of commercial cocoa powders. J Agric Food Chem 56, 8527-8533.

105. Serafini M, Ghiselli A \& Ferro-Luzzi A (1996) In vivo antioxidant effect of green and black tea in man. Eur J Clin Nutr 50, 28-32.

106. van het Hof KK, Kivits GA, Weststrate JA, et al. (1998) Bioavailability of catechins from tea: the effect of milk. Eur J Clin Nutr 52, 356-359.

107. Langley-Evans SC (2000) Consumption of black tea elicits an increase in plasma antioxidant potential in humans. Int $J$ Food Sci Nutr 51, 309-315.

108. Leenen R, Roodenburg AJ, Tijburg LB, et al. (2000) A single dose of tea with or without milk increases plasma antioxidant activity in humans. Eur J Clin Nutr 54, 87-92.

109. Willis LM, Shukitt-Hale B \& Joseph JA (2009) Recent advances in berry supplementation and age-related cognitve decline. Curr Opin Clin Nutr Metab Care 12, 91-94.

110. Andres-Lacueva C, Shukitt-Hale B, Galli RL, et al. (2005) Anthocyanins in aged blueberry-fed rats are found centrally and may enhance memeory. Nutr Neurosci 8, 111-120.

111. El Mohsen MA, Marks J, Kuhnle G, et al. (2006) Absorption, tissue distribution and excretion of pelargonidin and its metabolites following oral administration to rats. Br J Nutr 95, 51-58.

112. Borges G, Roowi S, Rouanet J-M, et al. (2007) The bioavailability of raspberry anthocyanins and ellagitannins in rats. Mol Nutr Food Res 51, 714-725.

113. Kalt W, Blumber JB, McDonald JE, et al. (2008) Identification of anthocyanins in the liver, eye, and brain of blueberry-fed pigs. J Agric Food Chem 56, 705-712. 
114. Matsumoto H, Nakamura Y, Iida H, et al. (2006) Comparative assessment of distribution of blackcurrant anthocyanins in rabbit and rat ocular tissues. Exp Eye Res 83, 348-356.

115. Mullen W, Larcombe S, Arnold K, et al. (2010) Use of accurate mass full scan mass spectrometry for the analysis of anthocyanins in berries and berry-fed tissues. J Agric Food Chem (In the Press).

116. Mullen W, Rouanet J-M, Auger C, et al. (2008) Bioavailability of $\left[2-{ }^{14} \mathrm{C}\right]$ quercetin- 4 -glucoside in rats. J Agric Food Chem 56, $12127-12137$.

117. Zini A, Del Rio D, Stewart AJ, et al. (2006) Do flavan-3-ols from green tea reach the human brain. Nutr Neurosci 9, $57-61$.

118. Kawa Y, Nishikawa T, Shiba Y, et al. (2008) Macrophage as a target of quercetin glucuronides in human atherosclerotic arteries. Implication in the anti-atherosclerotic mechanism of dietary flavonoids. J Biol Chem 283, 9424-9434.

119. Kawa Y, Tanaka H, Murota K, et al. (2008) (-)-Epicatechin gallate accumulates in foamy macrophages in human atherosclertic aorta: implication in the anti-atherosclerotic actions of tea catechins. Biochem Biophys Res Comm 374, 527-532.

120. Del Rio D, Costa LG, Lean ME, et al. (2009) Polyphenols and health: what compounds are involved? Nutr Metab Cardiovasc Dis 20, 1-6.

121. Hsu HY, Tsang SF, Lin KW, et al. (2008) Cell death induced by flavonoid glycosides with and without copper. Food Chem Toxicol 46, 2394-2401.

122. Bellion P, Hofmann T, Pool-Zobel BL, et al. (2008) Antioxidant effectiveness of phenolic apple juice extracts and their gut fermentation products in the human colon carcinoma cell line caco-2. J Agric Food Chem 56, 6310-6317.

123. Jaganath IB, Mullen W, Lean MEJ, et al. (2009) In vitro catabolism of rutin by human fecal bacteria and the antioxidant capacity of its catabolites. Free Radic Biol Med 47, $1180-1189$

124. Pellegrini N, Del Rio D, Colombi B, et al. (2003) Application of the 2,2'-azinobis(3-ethylbenzothiazoline-6-sulfonic acid) radical cation assay to a flow injection system for the evaluation of antioxidant activity of some pure compounds and beverages. J Agric Food Chem 51, 260-264.

125. González-Sarrías A, Azorín-Ortuño M, Yáñez-Gascón MJ, et al. (2009) Dissimilar in vitro and in vivo effects of ellagic acid and its microbiota-derived metabolites, urolithins, on the cytochrome P450 1A1. J Agric Food Chem 57, 5623-5632.

126. González-Sarrías A, Espín JC, Tomás-Barberán FA, et al. (2009) Gene expression, cell cycle arrest and MAPK signalling regulation in Caco-2 cells exposed to ellagic acid and its metabolites, urolithins. Mol Nutr Food Res 53, 686-698.

127. Larrosa M, González-Sarrías A, Yáñez-Gascón MJ, et al. (2009) Anti-inflammatory properties of a pomegranate extract and its metabolite urolithin-A in a colitis rat model and the effect of colon inflammation on phenolic metabolism. $J$ Nutr Biochem 21, 717-725.

128. Pellacani C, Calani L, Caglieri A, et al. (2009) Mild and intense oxidative stress of human neurons: protection exerted by colon-derived phenolic catabolites. In Proceedings of the 4th International Conference on Polyphenols and Health, Harrowgate, UK.

129. Youdim KA, Shukitt-Hale B \& Joseph JA (2004) Flavonoids and the brain: Interactions at the blood-brain barrier and their physiological effects on the central nervous system. Free Radic Biol Med 37, 1683-1693.

130. Larrosa M, Luceri C, Vivoli E, et al. (2009) Polyphenol metabolites from colonic microbiota exert anti-inflammatory activity on different inflammation models. Mol Nutr Food Res 53, $1044-1054$.
131. Aura AM, Martin-Lopez P, O’Leary KA, et al. (2005) In vitro metabolism of anthocyanins by human gut microflora. Eur J Nutr 44, 133-142.

132. Vitaglione P, Donnarumma G, Napolitano A, et al. (2007) Protocatechuic acid is the major human metabolite of cyanidin-glucosides. J Nutr 137, 2043-2048.

133. Galvano F, Vitaglione P, Li Volti G, et al. (2008) Protocatechuic acid: the missing human cyanidins' metabolite. Mol Nutr Food Res 52, 386-387.

134. Guan S, Ge D, Liu TQ, et al. (2009) Protocatechuic acid promotes cell proliferation and reduces basal apoptosis in cultured neural stem cells. Toxicol In vitro 23, 201-208.

135. Guan S, Jiang B, Bao YM, et al. (2006) Protocatechuic acid suppresses $\mathrm{MPP}^{+}$-induced mitochondrial dysfunction and apoptotic cell death in PC12 cells. Food Chem Toxicol 44, 1659-1666.

136. Lin HH, Chen JH, Huang CC, et al. (2007) Apoptotic effect of 3,4-dihydroxybenzoic acid on human gastric carcinoma cells involving JNK/p38 MAPK signalling activation. Int J Cancer 120, 2306-2316

137. Lala G, Malik M, Zhao C, et al. (2006) Anthocyanin-rich extracts inhibit multiple biomarkers of colon cancer in rats. Nutr Cancer 54, 84-93.

138. Stoner GD, Chen T, Kresty LA, et al. (2006) Protection against oesophageal cancer in rodents with lyophilized berries: potential mechanisms. Nutr Cancer 54, 33-46.

139. Chen T, Hwang H, Rose ME, et al. (2006) Chemopreventive properties of black raspberries in $N$-nitrosomethylbenzylamine-induced rat esophageal tumorigenesis: down-regulation of cyclooxygenase-2, inducible nitric oxide synthase, and c-Jun. Cancer Res 66, 2853-2859.

140. Wang LS, Hecht SS, Carmella SG, et al. (2009) Anthocyanins in black raspberries prevent esophageal tumors in rats. Cancer Prev Res (Phila Pa) 2, 84-93.

141. Gordillo G, Fang H, Khanna S, et al. (2009) Oral administration of blueberry inhibits angiogenic tumor growth and enhances survival of mice with endothelial cell neoplasm. Antioxid Redox Signal 11, 47-58.

142. Prasain JK, Jones K, Moore R, et al. (2008) Effect of cranberry juice concentrate on chemically-induced urinary bladder cancers. Oncol Rep 19, 1565-1570.

143. Aiyer HS, Srinivasan C \& Gupta RC (2008) Dietary berries and ellagic acid diminish estrogen-mediated mammary tumorigenesis in ACI rats. Nutr Cancer 60, 227-234.

144. Ahmet I, Spangler E, Shukitt-Hale B, et al. (2009) Blueberryenriched diet protects rat heart from ischemic damage. PLoS One 4, e5954.

145. Toufektsian MC, de Lorgeril M, Nagy N, et al. (2008) Chronic dietary intake of plant-derived anthocyanins protects the rat heart against ischemia-reperfusion injury. $J$ Nutr 138, 747-752.

146. Shin WH, Park SJ \& Kim EJ (2006) Protective effect of anthocyanins in middle cerebral artery occlusion and reperfusion model of cerebral ischemia in rats. Life Sci 79, 130-137.

147. Yamanouchi J, Nishida E, Itagaki S, et al. (2000) Aortic atheromatous lesions developed in APA hamsters with streptozotocin induced diabetes: a new animal model for diabetic atherosclerosis. 1 Histopathological studies. Exp Anim 49, 259-266.

148. Chambless LE, Folsom AR, Clegg LX, et al. (2000) Carotid wall thickness is predictive of incident clinical stroke: the Atherosclerosis Risk in Communities (ARIC) study. Am J Epidemiol 151, 478-487.

149. DeFuria J, Bennett G, Strissel KJ, et al. (2009) Dietary blueberry attenuates whole-body insulin resistance in high fat-fed mice by reducing adipocyte death and its inflammatory sequelae. J Nutr 139, 1510-1516. 
150. Roy M, Sen S \& Chakraborti AS (2008) Action of pelargonidin on hyperglycemia and oxidative damage in diabetic rats: implication for glycation-induced haemoglobin modification. Life Sci 82, 1102-1110.

151. Sasaki R, Nishimura N, Hoshino H, et al. (2007) Cyanidin 3-glucoside ameliorates hyperglycemia and insulin sensitivity due to downregulation of retinol binding protein 4 expression in diabetic mice. Biochem Pharmacol 74, 1619-1627.

152. Tsuda $\mathrm{T}$ (2008) Regulation of adipocyte function by anthocyanins; possibility of preventing the metabolic syndrome. J Agric Food Chem 56, 642-646.

153. Shukitt-Hale B, Carey A, Simon L, et al. (2006) Effects of Concord grape juice on cognitive and motor deficits in aging. Nutrition 22, 295-302.

154. Shukitt-Hale B, Cheng V \& Joseph JA (2009) Effects of blackberries on motor and cognitive function in aged rats. Nutr Neurosci 12, 135-140.

155. Duffy KB, Spangler EL, Devan BD, et al. (2008) A blueberryenriched diet provides cellular protection against oxidative stress and reduces a kainate-induced learning impairment in rats. Neurobiol Aging 29, 1680-1689.

156. Shukitt-Hale B, Lau FC, Carey AN, et al. (2008) Blueberry polyphenols attenuate kainic acid-induced decrements in cognition and alter inflammatory gene expression in rat hippocampus. Nutr Neurosci 11, 172-182.

157. Varadinova MG, Docheva-Drenska DI \& Boyadjieva NI (2009) Effects of anthocyanins on learning and memory of ovariectomized rats. Menopause 16, 345-349.

158. Shih PH, Chan YC, Liao JW, et al. (2009) Antioxidant and cognitive promotion effects of anthocyanin-rich mulberry (Morus atropurpurea L.) on senescence-accelerated mice and prevention of Alzheimer's disease. J Nutr Biochem 21, 598-605.

159. Shukitt-Hale B, Carey AN, Jenkins D, et al. (2007) Beneficial effects of fruit extracts on neuronal function and behavior in a rodent model of accelerated aging. Neurobiol Aging 28, $1187-1194$.

160. Hooper L, Kroon PA, Rimm EB, et al. (2008) Flavonoids, flavonoid-rich foods, and cardiovascular risk: a metaanalysis of randomized controlled trials. Am J Clin Nutr 88, $38-50$.

161. Rossi M, Negri E, Lagiou P, et al. (2008) Flavonoids and ovarian cancer risk: a case-control study in Italy. Int $J$ Cancer 123, 895-898.

162. Mursu J, Nurmi T, Tuomainen TP, et al. (2007) The intake of flavonoids and carotid atherosclerosis: the Kuopio Ischaemic heart disease Risk Factor Study. Br J Nutr 98, 814-818.

163. Mursu J, Nurmi T, Tuomainen TP, et al. (2008) Intake of flavonoids and risk of cancer in Finnish men: The Kuopio Ischaemic Heart Disease Risk Factor Study. Int J Cancer 123, 660-663.
164. Mursu J, Voutilainen S, Nurmi T, et al. (2008) Flavonoid intake and the risk of ischaemic stroke and CVD mortality in middle-aged Finnish men: the Kuopio Ischaemic Heart Disease Risk Factor Study. Br J Nutr 100, 890-895.

165. Hernández-Ramírez RU, Galván-Portillo MV, Ward MH, et al. (2009) Dietary intake of polyphenols, nitrate and nitrite and gastric cancer risk in Mexico City. Int $J$ Cancer 125, 1424-1430.

166. Frankenfeld CL, Cerhan JR, Cozen W, et al. (2008) Dietary flavonoid intake and non-Hodgkin lymphoma risk. Am J Clin Nutr 87, 1439-1445.

167. Møller P, Loft S, Alfthan G, et al. (2004) Oxidative DNA damage in circulating mononuclear blood cells after ingestion of blackcurrant juice or anthocyanin-rich drink. Mutat Res 551, 119-126.

168. Spormann TM, Albert FW, Rath T, et al. (2008) Anthocyanin/ polyphenolic-rich fruit juice reduces oxidative cell damage in an intervention study with patients on haemodialysis. Cancer Epidemiol Biomarkers Prev 17, 3372-3380.

169. Zern TL, Wood RJ, Greene C, et al. (2005) Grape polyphenols exert a cardioprotective effect in pre- and postmenopausal women by lowering plasma lipids and reducing oxidative stress. J Nutr 135, 1911-1917.

170. Traustadóttir T, Davies SS, Stock AA, et al. (2009) Tart cherry juice decreases oxidative stress in healthy older men and women. J Nutr 139, 1896-1900.

171. Castilla P, Echarri R, Dávalos A, et al. (2006) Concentrated red grape juice exerts antioxidant, hypolipidemic, and antiinflammatory effects in both hemodialysis patients and healthy subjects. Am J Clin Nutr 84, 252-262.

172. Matsumoto H, Takenami E, Iwasaki-Kurashige K, et al. (2005) Effects of blackcurrant anthocyanin intake on peripheral muscle circulation during typing work in humans. Eur $J$ Appl Physiol 94, 36-45.

173. Sumner MD, Elliott-Eller M, Weidner G, et al. (2005) Effects of pomegranate juice consumption on myocardial perfusion in patients with coronary heart disease. Am J Cardiol 96, 810-814.

174. Garcia-Alonso M, Minihane AM, Rimbach G, et al. (2009) Red wine anthocyanins are rapidly absorbed in humans and affect monocyte chemoattractant protein 1 levels and antioxidant capacity of plasma. $J$ Nutr Biochem 20, $521-529$

175. Kar P, Laight D, Rooprai HK, et al. (2009) Effects of grape seed extract in type 2 diabetic subjects at high cardiovascular risk: a double blind randomized placebo controlled trial examining metabolic markers, vascular tone, inflammation, oxidative stress and insulin sensitivity. Diabet Med 26, 526-531.

176. Jepson RG \& Craig JC (2008) Cranberries for preventing urinary tract infections. The Cochrane Database of Systematic Reviews 2008, issue 1, CD001321. http://mrw.interscience. wiley.com/cochrane/clsysrev/articles/CD001321/frame.html 